\title{
$\beta$ III Spectrin Is Necessary for Formation of the Constricted Neck of Dendritic Spines and Regulation of Synaptic Activity in Neurons
}

\author{
Nadia Efimova, ${ }^{1}$ Farida Korobova, ${ }^{1}$ @Michael C. Stankewich, ${ }^{2}$ Andrew H. Moberly, ${ }^{3}$ Donna B. Stolz, ${ }^{4}$ Junling Wang, ${ }^{5}$ \\ Anna Kashina, ${ }^{5}$ Minghong $\mathrm{Ma}^{3}$ and Tatyana Svitkina ${ }^{1}$ \\ ${ }^{1}$ Department of Biology, University of Pennsylvania, Philadelphia, Pennsylvania 19104, ${ }^{2}$ Department of Pathology, Yale University School of Medicine, \\ New Haven, Connecticut 06510, ${ }^{3}$ Department of Neuroscience, University of Pennsylvania Perelman School of Medicine, Philadelphia, Pennsylvania 19104, \\ ${ }^{4}$ Center for Biologic Imaging, University of Pittsburgh School of Medicine, Pittsburgh, Pennsylvania 15261, and ${ }^{5}$ Department of Animal Biology, \\ University of Pennsylvania School of Veterinary Medicine, Philadelphia, Pennsylvania 19104
}

Dendritic spines are postsynaptic structures in neurons often having a mushroom-like shape. Physiological significance and cytoskeletal mechanisms that maintain this shape are poorly understood. The spectrin-based membrane skeleton maintains the biconcave shape of erythrocytes, but whether spectrins also determine the shape of nonerythroid cells is less clear. We show that $\beta$ III spectrin in hippocampal and cortical neurons from rodent embryos of both sexes is distributed throughout the somatodendritic compartment but is particularly enriched in the neck and base of dendritic spines and largely absent from spine heads. Electron microscopy revealed that $\beta$ III spectrin forms a detergent-resistant cytoskeletal network at these sites. Knockdown of $\beta$ III spectrin results in a significant decrease in the density of dendritic spines. Surprisingly, the density of presynaptic terminals is not affected by $\beta$ III spectrin knockdown. However, instead of making normal spiny synapses, the presynaptic structures in $\beta$ III spectrin-depleted neurons make shaft synapses that exhibit increased amplitudes of miniature EPSCs indicative of excessive postsynaptic excitation. Thus, $\beta$ III spectrin is necessary for formation of the constricted shape of the spine neck, which in turn controls communication between the synapse and the parent dendrite to prevent excessive excitation. Notably, mutations of SPTNB2 encoding $\beta$ III spectrin are associated with neurodegenerative syndromes, spinocerebellar ataxia Type 5 , and spectrin-associated autosomal recessive cerebellar ataxia Type 1, but molecular mechanisms linking $\beta$ III spectrin functions to neuronal pathologies remain unresolved. Our data suggest that spinocerebellar ataxia Type 5 and spectrin-associated autosomal recessive cerebellar ataxia Type 1 pathology likely arises from poorly controlled synaptic activity that leads to excitotoxicity and neurodegeneration.

Key words: cytoskeleton; dendritic spines; electron microscopy; hippocampal neurons; spectrin; synapse

\section{Significance Statement}

Dendritic spines are small protrusions from neuronal dendrites that make synapses with axons of other neurons in the brain. Dendritic spines usually have a mushroom-like shape, which is essential for brain functions, because aberrant spine morphology is associated with many neuropsychiatric disorders. The bulbous head of a mushroom-shaped spine makes the synapse, whereas the narrow neck transmits the incoming signals to the dendrite and supposedly controls the signal propagation. We show that a cytoskeletal protein $\beta$ III spectrin plays a key role for the formation of narrow spine necks. In the absence of $\beta$ III spectrin, dendritic spines collapse onto dendrites. As a result, synaptic strength exceeds acceptable levels and damages neurons, explaining pathology of human syndromes caused by $\beta$ III spectrin mutations.

\section{Introduction}

Excitatory neuronal synapses are often formed between axonal presynaptic boutons and postsynaptic dendritic spines. A typical mushroom-like shape of dendritic spines is important for ef- ficient synaptic transmission. Accordingly, multiple neuropsychiatric disorders are associated with structural alterations in dendritic spines (Penzes et al., 2011). The wide head of a mushroom-shaped spine interacts with the axon and responds to 
neurotransmitters via the postsynaptic density (PSD), a large collection of signaling proteins at the junction with the axon (Sala and Segal, 2014). A constricted spine neck is thought to act as a diffusion barrier to compartmentalize excitatory signals (Tønnesen and Nagerl, 2016). This idea is experimentally supported by correlation between the diameter of the spine neck and diffusivity of fluorescent markers (Takasaki and Sabatini, 2014; Tønnesen et al., 2014) and by stimulation-induced changes in the dendritic spine morphology (Tønnesen et al., 2014). The cytoskeletal mechanisms maintaining the constricted shape of spine necks remain unclear because, in contrast to a robust branched actin network in the spine head, spine necks contain a rather loose and apparently weak actin cytoskeleton (Korobova and Svitkina, 2010). Interestingly, unidentified thin fibrils were found in greater amounts in dendritic spine necks relative to spine heads, and proposed to maintain the neck shape (Landis and Reese, 1983).

Spectrins are actin filament cross-linking proteins that typically function as $\alpha / \beta$ heterotetramers (Machnicka et al., 2014), which have actin-binding domains at their ends and various membrane-interacting sites along the length (Bennett and Lorenzo, 2016). Spectrin's functions are best characterized in erythrocytes, where the $2 \mathrm{D}$ membrane-bound actin-spectrin network maintains the biconcave cell shape (Fowler, 2013). Spectrins are also present in other cells and are especially important for the nervous system (Mazock et al., 2010), but their functions in nonerythroid cells are less well characterized.

The neurodegenerative disorders spinocerebellar ataxia Type 5 (SCA5) (Ikeda et al., 2006; Perkins et al., 2016) and spectrinassociated autosomal recessive cerebellar ataxia Type 1 (SPARCA1) (Lise et al., 2012) are linked to mutations in the SPTBN2 gene encoding $\beta$ III spectrin. At the cellular level, $\beta$ III spectrin deficiency is characterized by impaired dendrite development, sparse dendritic spines (Stankewich et al., 2010; Gao et al., 2011; Lise et al., 2012), and aberrant synaptic transmission in the cerebellum (Perkins et al., 2010). However, molecular mechanisms linking $\beta$ III spectrin functions to neurodegeneration remain largely unresolved because various proposed scenarios can be challenged by strong counterarguments (Perkins et al., 2016).

Here, we aimed to understand cellular functions of $\beta$ III spectrin in neurons. Our results suggest that $\beta$ III spectrin modulates synaptic function by maintaining the constricted shape of the dendritic spine neck. When $\beta$ III spectrin is dysfunctional, spiny synapses transform into shaft synapses leading to excessive neuronal activity, which may cause excitotoxicity and neurodegeneration in SCA5 and SPARCA1 syndromes.

\section{Materials and Methods}

Neuron culture. Dissociated rat embryo hippocampal and cortical neurons isolated as described previously (Wilcox et al., 1994) were obtained from the MINS Neuron Culture Service Center (University of Pennsylvania, Philadelphia). In brief, hippocampi or cortices were dissected from brains of Sprague Dawley rat embryos at embryonic day 18-20 and dissociated into individual cells by incubating in a trypsin-containing solution. The cells were then washed and plated on poly-L-lysine-coated

neurons; Dr. Nicholas Betley for help with Vibratome sectioning; Dr. Andrea Stout for help with Leica confocal microscope; Dr. Andrey Efimov for help with cloning; and members of the Svitkina laboratory for discussions.

The authors declare no competing financial interests.

Correspondence should be addressed to Dr. Tatyana Svitkina, 415 S. University Avenue, 304K Lynch Labs, Philadelphia, PA 19104. E-mail: svitkina@sas.upenn.edu.

F. Korobova's current address: Center for Advance Microscopy, Northwestern University Feinberg School of Medicine, Chicago, IL 60611.

DOI:10.1523/JNEUROSCI.3520-16.2017

Copyright $\odot 2017$ the authors $\quad 0270-6474 / 17 / 376443-18 \$ 15.00 / 0$
( $1 \mathrm{mg} / \mathrm{ml}$ ) glass coverslips at a concentration of 150,000 cells per $35 \mathrm{~mm}$ dish in $1.5 \mathrm{ml}$ neurobasal medium (Invitrogen) with 2\% B27 supplement. For correlative light microscopy and platinum replica electron microscopy (PREM) (Svitkina, 2016), hippocampal neurons were plated at a concentration of 80,000 cells per dish on $35 \mathrm{~mm}$ glassbottomed dishes containing coverslips that were coated with carbon through a finder grid to introduce fiducial marks.

Antibodies. The following rabbit polyclonal primary antibodies were used: $\beta$ III spectrin C terminus (sc-28273, Santa Cruz Biotechnology), $\beta$ III spectrin amino acid residues 1019-1464 (Stankewich et al., 1998), $\beta$ II spectrin (gift from Dr. Vann Bennett), MAP2 (AB5622, Millipore), synapsin I (106103, Synaptic Systems), synaptophysin (Ab-4, Neo Markers), GFP (A-6455, Invitrogen), and septin 7 (18991, IBL-America). The following primary mouse monoclonal antibodies were used: MAP2 (M2320, Sigma), PSD95, clone 6G6-1C9 (ab2723, Abcam), PSD95, clone K28/43 (73-028, Neuromab), pan-axonal marker SMI312 (SMI-312R, Covance), $\beta 3$ tubulin (clone Tuj1, MMS-435P, Covance), and $\alpha$-tubulin (clone DM1 $\alpha$, T-6199, Sigma). Secondary antibodies and phalloidin fluorescently labeled with AlexaFluor-488, -594, and -680 were from Invitrogen; secondary anti-rabbit and anti-mouse IgG antibodies conjugated to 12 or $18 \mathrm{~nm}$ colloidal gold were from Jackson ImmunoResearch Laboratories; and HRP-linked ECL anti-mouse (NA931V) and anti-rabbit (NA934V) IgG antibodies were from GE Healthcare.

Immunocytochemistry. For immunofluorescence staining of mouse brain tissue, perfusion-fixed brains were postfixed for $4-24 \mathrm{~h}$ in $4 \%$ formaldehyde. For Figure $1 C$, fixed tissue was embedded into paraffin. Tissue sections were deparaffinized in xylene and rehydrated with $100 \%$ ethanol and PBS. Antigen retrieval was performed in a pressure cooker using $6.5 \mathrm{~mm}$ sodium citrate, $\mathrm{pH}$ 6.0. Sections were incubated with primary $\beta$ III spectrin antibodies (Stankewich et al., 1998) diluted in PBS with $2 \%$ BSA and $0.1 \%$ saponin. Fluorescently labeled secondary antibodies were used at 1:1000. For Figure $3 A, 50-\mu \mathrm{m}$-thick Vibratome sections of hippocampus were stained with phalloidin and $\beta$ III spectrin antibody (Stankewich et al., 1998) and imaged by spinning disk confocal microscopy. For Figure $3 B, 5-\mu \mathrm{m}$-thick cryosections of the cerebellum were stained with phalloidin and $\beta$ III spectrin antibody (Stankewich et al., 1998) and imaged by laser-scanning confocal microscopy. Immunofluorescence staining of neuronal cultures was performed after fixation with $4 \%$ formaldehyde (Electron Microscopy Sciences) in PBS for $15 \mathrm{~min}$ and permeabilization with $0.3 \%$ Triton for $5 \mathrm{~min}$ or after simultaneous fixation and permeabilization with a mixture of $4 \%$ formaldehyde and $0.3 \%$ Triton X-100 for $10 \mathrm{~min}$.

Laser-scanning confocal fluorescence microscopy was performed using Leica TCS SP8 confocal microscope equipped with $63 \times 1.4$ NA oil-immersion objective, 405, 488, 552, and $638 \mathrm{~nm}$ excitation laser lines, and PMT and HyD detectors driven by LAS software. Wide-field fluorescence microscopy was performed using Nikon Eclipse TE2000 inverted microscope equipped with Plan Apo $100 \times 1.3$ NA oil-immersion objective and Cascade 512B CCD camera (Roper Scientific) driven by MetaMorph imaging software (Molecular Devices). Spinning disk confocal microscopy was performed using Nikon Eclipse Ti inverted microscope equipped with CFI60 Apochromat TIRF $100 \times 1.49$ NA oil objective and QuantEM 512SC digital camera (Photometrics) driven by NIS-Elements software (Nikon).

$E M$. For immuno-EM of mouse brain tissue, mouse brains were fixed in $2 \%$ formaldehyde in PBS at $4^{\circ} \mathrm{C}$ for $1 \mathrm{~h}$. Tissue was cryoprotected in $30 \%$ sucrose overnight at $4^{\circ} \mathrm{C}$, frozen in liquid nitrogen-cooled 2-methylpentane, and stored at $-80^{\circ} \mathrm{C}$ until use. Cryosections $(\sim 10 \mu \mathrm{m})$ were cut, affixed to charged (Superfrost/Plus, Fisher) slides, and allowed to adhere to the slides overnight at $-20^{\circ} \mathrm{C}$. Sections were washed three times with PBS, then three times with PBS containing 0.5\% BSA, $0.15 \%$ glycine, and $0.05 \%$ Tween 20 (PBGT buffer) followed by a 30 min blocking incubation with $5 \%$ normal goat serum in PBGT. Sections were labeled with $\beta$ III spectrin antibody (Stankewich et al., 1998) at a dilution of 1:100 in PBGT overnight at $4^{\circ} \mathrm{C}$, washed four times in PBGT, incubated with goat anti-rabbit secondary antibodies conjugated to $5 \mathrm{~nm}$ gold (Sigma) at a dilution of 1:10 for $4 \mathrm{~h}$, washed three times in PBGT, then three times in PBS, fixed in 2.5\% glutaraldehyde in PBS for 15 min, washed two times in PBS, postfixed with $1 \%$ aqueous osmium tetroxide 
and $1 \%$ potassium ferricyanide for $1 \mathrm{~h}$, washed three times with PBS, dehydrated through a graded series of ethanols (30\%-100\%), and infiltrated with four changes of Polybed 812 resin (Polysciences) over $4 \mathrm{~h}$ at room temperature. Sections were embedded by inverting filled Beam capsules over the section and allowing the resin to cure overnight at $37^{\circ} \mathrm{C}$ followed by 2 additional days at $65^{\circ} \mathrm{C}$. Thick sections $(300 \mathrm{~nm})$ were heated onto glass slides, stained with toluidine blue, and examined by light microscopy to assure proper orientation. Ultrathin $(70 \mathrm{~nm}) \mathrm{sec}-$ tions were collected on 100 mesh copper grids and were not poststained.

Sample preparation for PREM, correlative light and EM, immunogold PREM, and S1 decoration were performed as described previously (Svitkina, 2007, 2016). In brief, detergent-extracted samples were sequentially fixed with $2 \%$ glutaraldehyde in $0.1 \mathrm{M} \mathrm{Na}$-cacodylate buffer, $\mathrm{pH} 7.3,0.1 \%$ tannic acid, and $0.2 \%$ uranyl acetate; critical point dried; coated with platinum and carbon; and transferred onto 50 mesh electron microscopic grids for observation. For nonextracted samples, neuronal cultures were directly fixed with glutaraldehyde and processed the same way. Detergent extraction was done with $1 \%$ Triton X-100 in PEM buffer (100 mm PIPES-KOH, pH 6.9, $1 \mathrm{~mm} \mathrm{MgCl}_{2}$, and 1 mm EGTA) containing $2 \%$ polyethelene glycol (molecular weight of 35,000$), 2 \mu \mathrm{M}$ phalloidin, and $10 \mu \mathrm{m}$ taxol for $3 \mathrm{~min}$ at room temperature. For S1 decoration, detergent-extracted unfixed cells were incubated with $0.25 \mathrm{mg} / \mathrm{ml} \mathrm{S1}$ (gift of Dr. Yale E. Goldman, University of Pennsylvania) in PEM buffer with $5 \mu \mathrm{M}$ phalloidin for $30 \mathrm{~min}$ at room temperature and fixed with $2 \%$ glutaraldehyde.

For $\beta$ III spectrin (C terminus) immunogold PREM, primary antibody in PEM buffer with $2 \mu \mathrm{M}$ unlabeled phalloidin and $10 \mu \mathrm{M}$ taxol was added for 30 min either to extracted unfixed cells or to cells extracted with the above extraction solution, but supplemented with $0.5 \%$ formaldehyde. For synaptophysin immunogold staining, cells were fixed with $0.2 \%$ glutaraldehyde in Na-cacodylate buffer, treated with $0.05 \%$ Triton X-100 for 1 min, quenched with $\mathrm{NaBH}_{4}$, incubated with primary antibody in PBS for $30 \mathrm{~min}$, fixed with $0.2 \%$ glutaraldehyde, quenched with $2 \mathrm{mg} / \mathrm{ml} \mathrm{NaBH}_{4}$ in PBS for $10 \mathrm{~min}$, stained with secondary colloidal gold-conjugated antibody, and fixed with $2 \%$ glutaraldehyde for at least $20 \mathrm{~min}$.

PREM and thin-section EM samples were analyzed using JEM 1011 transmission electron microscope (JEOL) operated at $100 \mathrm{kV}$. Images were captured by ORIUS $832.10 \mathrm{~W}$ CCD camera (Gatan). PREM images are presented in inverted contrast. Identification of gold particles in PREM samples was performed at high magnification after contrast enhancement to distinguish them from other bright objects in the samples. Color labeling and image overlays were performed using Photoshop (Adobe Systems), as described previously (Shutova et al., 2012).

Western blotting. Dissected brain tissue from 12-month-old male rats was washed in ice-cold PBS and snapped frozen in liquid nitrogen. For lysate preparation, tissue was thawed on ice and homogenized with 18 gauge needle in the ice-cold lysis buffer (100 mM PIPES, $150 \mathrm{~mm} \mathrm{NaCl}$, 0.5 mм EDTA, $1 \%$ Triton X-100, pH 7.1), followed by incubation for 30 min on ice. Rat hippocampal neurons grown on $35 \mathrm{~mm}$ dishes were lysed in a buffer containing $20 \mathrm{~mm}$ HEPES, pH 6.9, $150 \mathrm{~mm} \mathrm{KCl,} 2 \mathrm{~mm} \mathrm{MgCl}$, $1 \mathrm{~mm}$ DTT, and $0.5 \%$ Triton X-100. After clarification of lysates by centrifugation at $13,000 \times g$ for $10 \mathrm{~min}$ at $4^{\circ} \mathrm{C}$, the protein concentration in supernatants was determined using Protein Assay (500-0006, Bio-Rad). Protein samples were mixed with the NuPAGE sample buffer (Invitrogen, catalog \#NP0007) supplemented with DTT to a final concentration of $200 \mathrm{~mm}$ and boiled for $5 \mathrm{~min}$. Approximately $25 \mu \mathrm{g}$ (for tissue lysates) or $20 \mu \mathrm{g}$ (for cell lysates) of total protein was loaded onto $3 \%-8 \% \mathrm{Nu}-$ PAGE TA 1.0 gradient gels (EA0375, Invitrogen), resolved by SDSPAGE, and transferred to $0.45 \mu \mathrm{m}$ PVDF membrane in NuPAGE Transfer Buffer overnight at $15 \mathrm{~V}$ and additional $2 \mathrm{~h}$ at $30 \mathrm{~V}$ using the $\mathrm{X}$ Cell SureLock Electrophoresis and Western Blotting System (Invitrogen). The membrane was blocked with 5\% milk in TBS (170-6435, BioRad) containing $0.1 \%$ Tween 20 (P7949, Sigma) for $1 \mathrm{~h}$, incubated with primary antibodies in TBS/Tween 20 (1/1000 dilution for $\beta$ III spectrin and Tuj1 antibodies and $1 / 20,000$ for $\beta$ II spectrin and DM1 $\alpha$ antibodies) for $2 \mathrm{~h}$, washed in TBS/Tween 20, incubated with secondary antibodies (1/10,000 dilution) for $40 \mathrm{~min}$, and developed with ECL Western Blotting Detection Reagent (RPN2232, GE Healthcare). Intensity of the protein bands was measured using MetaMorph software.
Quantitative RT-PCR. Homogenization of isolated rat brain tissue (cerebellum, hippocampus, and cerebral cortex) and isolation of total RNA were performed using RNeasy Mini Kit (QIAGEN, catalog \#74104). Reverse transcription was performed by using the High Capacity cDNA Reverse Transcription Kit (Applied Biosystems, AB, catalog \#4368814). Real-time PCR was performed using the SYBR-Green-based detection in a Roche lightcycler 5.2 (Roche Applied Science) using specific primers for SPTB (forward: 5' -AGCAGAGGCAGGAGACACG-3', reverse: $5^{\prime}$ GCTGCACTGTTTGCAGATTAG-3'); SPTBN1 (forward: 5'-GAGG GAAACTTGATGAGAGG'， reverse: 5'-TGCCATGTGGTTAACTGT ATCT-3'); SPTBN2 (forward: 5'-TGCAGAGGCCGAGGCTTGG-3', reverse: $5^{\prime}$-CCTTGTGCTCTCTGGATGTT-3'); and tubulin (forward: 5'-TACCCTCGCATCCACTTCCCT-3', reverse: 5' -CGCTTGGTCTTG ATGGTGGCA-3'). Quantitative PCR cycling conditions were as follows: initial denaturation at $95^{\circ} \mathrm{C}$ for $1 \mathrm{~min}, 50$ cycles of $95^{\circ} \mathrm{C}$ for $1 \mathrm{~s}$, and $68^{\circ} \mathrm{C}$ for $25 \mathrm{~s}$, followed by dissociation curve analysis. Each sample was run in triplicate and normalized relative to tubulin expression levels. The comparative Ct $(\Delta \Delta \mathrm{CT})$ method was used for quantification of relative mRNA levels.

Plasmids and transfection. The following short hairpin RNA (shRNA) sequences were used to target $\beta$ III spectrin: $5^{\prime}$-GCGGAAGCATGAAGC CATTGA-3' (sh\#1) and 5'-GCAGCAGCACTTCTTGCAAGA-3' (sh\#2). The sequence $5^{\prime}$-CTACTGAGAACTAAGAGAG-3' (shc) was used as nontargeting control (Hartman et al., 2006). Oligos for shRNA construction were obtained from Integrated DNA Technologies and cloned into $\mathrm{HpaI}$ and XhoI restriction enzyme sites of the lentiviral pLL-Cerulean 5.0 vector (kindly provided by Dr. A. Efimov, Fox Chase Cancer Center, Philadelphia) (Smalley-Freed et al., 2010).

For producing lentiviral particles, plasmids containing shRNA sequences or $\beta$ III spectrin deletion mutants were cotransfected together with helper plasmids MD2G and Pax2 into HEK293T cells using FuGENE6 (Roche). Virus was harvested on the third day after transfection and immediately applied to hippocampal neurons at DIV11 together with $5 \mu \mathrm{g} / \mathrm{ml}$ Protamine Sulfate (P4020, Sigma). Culture medium was replaced after $6-8 \mathrm{~h}$ incubation with the virus, and cells were cultured for additional $6 \mathrm{~d}$ before analysis.

Lipofectamine LTX (15338-100, Invitrogen) was used for transient transfection of pEGFP-tagged full-length $\beta$ III spectrin according to the manufacturer's instructions. Specifically, $1 \mu \mathrm{g}$ of DNA was diluted in $100 \mu \mathrm{l}$ of serum-free DMEM supplemented with $2.5 \mu \mathrm{l}$ of Lipofectamine LTX reagent. Mixture was incubated for $30 \mathrm{~min}$ at room temperature, applied to $10-11$ DIV rat hippocampal neurons for $2.5 \mathrm{~h}$, and then replaced with culture medium.

Patch clamp. Electrophysiological recordings were performed on 17 DIV hippocampal neurons $6 \mathrm{~d}$ after transfection with a nontargeting shRNA or a $\beta$ III spectrin-targeting shRNA. Glass coverslips were transferred to a recording chamber continuously perfused with oxygenated Ringer's solution ( $124 \mathrm{~mm} \mathrm{NaCl}, 3 \mathrm{~mm} \mathrm{KCl}, 1.3 \mathrm{~mm} \mathrm{MgSO}_{4}, 2 \mathrm{~mm} \mathrm{CaCl}_{2}$, $26 \mathrm{~mm} \mathrm{NaHCO}_{3}, 1.25 \mathrm{~mm} \mathrm{NaH}_{2} \mathrm{PO}_{4}, 5.5 \mathrm{~mm}$ glucose; osmolarity adjusted to match culture medium $\sim 243 \mathrm{mOsm}$ and $\mathrm{pH} \sim 7.5$, bubbled with a mixture of $95 \% \mathrm{O}_{2}$ and $5 \% \mathrm{CO}_{2}$ ) with $1 \mu \mathrm{M}$ TTX. Whole-cell patch-clamp recordings were performed under differential interference contrast microscopy on an upright microscope (Olympus BX61WI). Patch pipettes $(5-10 \mathrm{M} \Omega$ ) were pulled from borosilicate glass $(1.2 \mathrm{~mm}$ outer diameter) and filled with a solution containing $120 \mathrm{~mm}$ K-gluconate, $10 \mathrm{~mm} \mathrm{NaCl}, 1 \mathrm{~mm} \mathrm{CaCl}$, 5 mm Mg-ATP, $0.5 \mathrm{~mm} \mathrm{Na}$-GTP, 10 mm EGTA, $10 \mathrm{~mm}$ HEPES, and $10 \mathrm{~mm}$ phosphocreatine. Signals were acquired with an EPC-9 amplifier run by Pulse software (HEKA Instruments). Analysis of spontaneous miniature synaptic currents (amplitude and frequency) was performed offline with custom routines in MATLAB (The MathWorks). The threshold for event detection was set at 3 times of the root mean square noise, and all events were visually confirmed.

Image analysis and statistics. Measurements were done using MetaMorph (for Western blots) or Fiji (for image analyses) software. Statistical analyses were performed using Instat software (GraphPad Software).

The $\beta$ III spectrin-positive dendritic protrusions in immunofluorescence images of cultured neurons stained with $\beta$ III spectrin antibody and phalloidin (see Fig. 2C) were visually identified, manually counted, and presented as a percentage of all actin-rich protrusions in the sample 
detected by phalloidin staining. Subspine distributions of $\beta$ III spectrin in dendritic spines stained with phalloidin and $\beta$ III spectrin antibody (see Fig. $2 G$ ) were quantified using intensity profiles obtained from confocal $Z$-stacks. Three or four confocal slices containing a suitably oriented dendrite segment were summed for analysis. Fluorescence intensity profiles of phalloidin and $\beta$ III spectrin staining were acquired along the dendritic spine axis starting from the middle of the parent dendrite. Dual-color intensity profiles were categorized into two groups: (1) "proximal" $\beta$ III spectrin localization characterized by $\beta$ III spectrin intensity persistently decreasing with distance from the dendrite with occasional formation of a secondary peak positioned behind the peak of phalloidin staining; and (2) "bimodal" $\beta$ III spectrin distribution, when $\beta$ III spectrin is high at the base, but also forms a secondary peak in the head that coincides with the phalloidin peak. For quantification of immunogold $\beta$ III spectrin labeling in thin sections, the shortest distance was measured between an individual gold particle within the labeled spine and the postsynaptic membrane in the same spine using spines labeled by at least one gold particle. The same spines were used to measure the thickness of the PSD.

The densities of dendritic spines and PSD95-positive puncta (see Fig. 5) were determined by thresholding images and quantifying the number of phalloidin- or PSD95-positive regions of interest (ROIs) in an individual image, measuring the total length of MAP2-positive dendrites in the same image using the Fiji selection tool and calculating the number of dendritic spines per $100 \mu \mathrm{m}$ of the dendrite length. Similar procedures were used to quantify densities of synapsin I-positive puncta per $100 \mu \mathrm{m}$ length of SMI312-positive axons (see Fig. 6D). The percentages of spiny synapses (see Fig. $6 E$ ) were determined by overlaying phalloidin-stained images with ROIs generated from thresholded images of MAP2 and PSD95 staining, counting the numbers of bright PSD95 regions associated either with dendritic spines or with dendrite shafts and calculating the fraction of spine-associated PSDs.

To evaluate synapse formation in control and $\beta$ III spectrin-depleted cells (see Fig. 6F), 17 DIV neurons were fixed and stained for synapsin I to visualize presynaptic boutons and for PSD95 to detect postsynaptic sites. Synapsin I-stained images were thresholded to outline fluorescent puncta. Two different thresholds were applied to PSD95-stained images: one to reveal only bright puncta (high threshold) and the other to include faint signals (low threshold). To quantify strong synapses, ROIs from the synapsin I channel were combined with high threshold ROIs from the PSD95 image and contacting regions from two channels were counted. To quantify weak synapses, ROIs from the synapsin I channel were combined with low threshold ROIs from the PSD95 image, contacting regions from two channels were counted giving a sum of strong and weak synapses, and the number of strong synapses was subtracted from this number to produce a result for weak synapses. Synapsin I ROIs that did not contact even low threshold PSD95 ROIs were categorized as "noncontacting” synapsin I puncta. Different categories of synapsin I puncta were presented as percentage of all synapsin I puncta.

To determine morphological parameters of dendritic spines in PREM images, the spine length was measured from bottom of the base to the tip of the head; the width of dendritic spine head was measured at the widest region; the width of the spine base was measured between points at which the spine outline began to deviate from the direction of the dendrite edge, and the thickness of the spine neck was measured at its narrowest region.

\section{Results \\ $\beta$ III spectrin is expressed in the hippocampus and cultured hippocampal neurons}

Rat hippocampal neurons appear as a good system to reveal functions of $\beta$ III spectrin because they readily differentiate in culture (Dotti et al., 1988) and have been broadly used to reveal functions of various neuronal proteins. However, expression of $\beta \mathrm{III}$ spectrin in the hippocampus and hippocampal neurons is not fully characterized. It is known that $\beta$ III spectrin (SPTBN2) is highly expressed in the brain and skin but also present in several other organs (Ohara et al., 1998; Uhlen et al., 2015). Within the brain, $\beta$ III spectrin has highest expression in the cerebellum (Ikeda et al., 2006; Perkins et al., 2010; Stankewich et al., 2010; Gao et al., 2011) but is also present in various brain tissues, including the hippocampus (Ohara et al., 1998; Stankewich et al., 2010; Uhlen et al., 2015). To better characterize expression of $\beta$-spectrins in the brain, we analyzed different regions of the rat brain by RT-PCR (Fig. $1 A$ ) and Western blotting (Fig. $1 B$ ). We found that $\beta$ II spectrin (SPTBN1) was the predominant $\beta$-spectrin paralog in the hippocampus, cerebellum, and cerebral cortex. However, $\beta$ III spectrin expression was also readily detectable both at mRNA and protein levels in all three tissues, in agreement with the Human Protein Atlas data (Uhlen et al., 2015). Erythroid spectrin $\beta \mathrm{I}$ (SPTB) was also expressed in these brain regions. Significant expression of $\beta$ III spectrin in the CA1 region of the mouse hippocampus was also detected by immunofluorescence staining (Fig. 1C). These data revealed that the somas and axons of pyramidal cells (stratum pyramidale) were largely unstained, whereas dendrites and dendritic protrusions in the stratum oriens and stratum radiatum were strongly immunopositive.

We next evaluated expression of $\beta$ III spectrin in cultured hippocampal neurons. The differentiation pattern of hippocampal neurons in culture involves specification of the axon that occurs after 2-3 DIV followed by the formation of dendrites at 5-7 DIV. Dendritic spines typically appear in substantial numbers at $\sim 14$ DIV and are thought to form from dendritic filopodia (Papa et al., 1995; Ethell and Pasquale, 2005), which are numerous at 7-11 DIV. By probing cell lysates prepared from cultured rat hippocampal neurons at 7,14 , and 21 DIV with $\beta$ III spectrin antibody (Fig. $1 D$ ), we found that expression levels of $\beta$ III spectrin gradually increased during neuron differentiation and approximately correlated with known stages of dendritic spine development. Specifically, $\beta$ III spectrin expression was low at 7 DIV, when dendritic spines are absent, increased at 14 DIV, when spines typically begin to form, and further increased at 21 DIV, when dendritic spines are abundant.

Together, these data establish that cultured hippocampal neurons can be used for analyses of cellular functions of $\beta$ III spectrin. However, we also performed key experiments in cultured cortical neurons because $\beta$ III spectrin is highly expressed in the cerebral cortex (Fig. 1A,B).

\section{$\beta$ III spectrin is expressed in the somatodendritic compartment and enriched at the base and neck of dendritic spines}

It is well established that in the cerebellum $\beta$ III spectrin localizes to the somatodendritic compartment of Purkinje neurons (Ohara et al., 1998; Jackson et al., 2001; Stankewich et al., 2010; Gao et al., 2011). However, subcellular localization of $\beta$ III spectrin in other neurons has not been evaluated. We determined subcellular distribution of endogenous $\beta$ III spectrin in 17 DIV hippocampal (Fig. 1E,F) and cortical (data not shown) neurons, which exhibit abundant dendritic spines. Double immunofluorescence labeling of $\beta$ III spectrin together with either an axonal (SMI312) or a dendritic (MAP2) marker revealed that $\beta$ III spectrin is present in the soma and dendrites, but was virtually excluded from axons (Fig. 1E,F). Compared with the intracellular distribution of MAP2 that associates with microtubules, the $\beta$ III spectrin pattern in the somatodendritic compartment closely resembled plasma membrane localization, which was especially visible at the soma periphery (Fig. $1 E$, enlarged panels).

Earlier studies of $\beta$ III spectrin localization in tissue sections of the cerebellum did not yield information about subspine distribution of $\beta$ III spectrin, whereas immunostaining of $\beta$ III spectrin in cultured Purkinje neurons suggested that it might be localized 

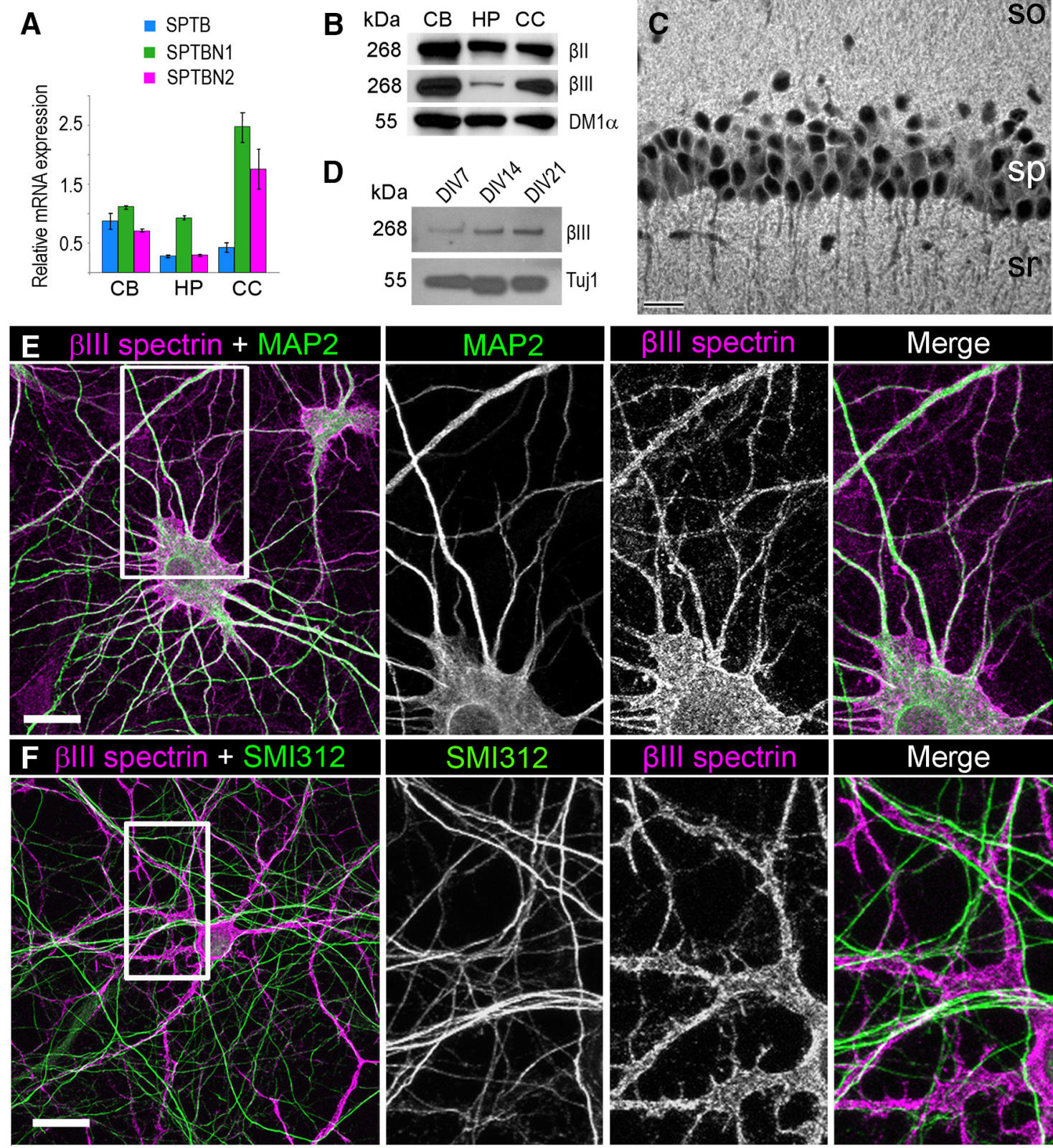

Figure 1. $\quad \beta \| I I$ spectrin is expressed in the hippocampus and cultured hippocampal neurons and localizes to the somatodendritic compartment. $A$, Quantitative RT-PCR of $\beta$ I (SPTB), $\beta \|$ (SPTBN1), and $\beta$ III (SPTNB2) spectrins in the adult rat cerebellum (CB), hippocampus (HP), and cerebral cortex (CC). Data from two wild-type rats in triplicates are normalized to the expression of tubulin. Error bars indicate SEM. B. Western blots of $\beta \|$ and $\beta$ III spectrins in lysates of adult rat cerebellum (CB), hippocampus (HP), and cerebral cortex (CC); $\alpha$-tubulin (clone DM1 $\alpha$ ) is used as loading control. C, Immunofluorescence staining of CA1 region of the mouse hippocampus with $\beta$ III spectrin antibody. White represents $\beta$ III spectrin localization. so, Stratum oriens; sp, stratum pyramidale; sr, stratum radiatum. D. Western blot of $\beta$ III spectrin in cell lysates prepared from 7, 14, and 21 DIV hippocampal neurons; tubulin $\beta 3$ (clone Tuj1) is used as loading control. E, $F$, Immunofluorescence staining of 17 DIV hippocampal neurons with antibodies to $\beta$ III spectrin (magenta) and either the dendritic marker MAP2 (E, green) or the axonal marker SMI312 (F, green). Left panels, Boxed areas are zoomed in right panels as individual channels and merged images. Bars, $20 \mu \mathrm{m}$.

throughout the dendritic spines (Gao et al., 2011). To better characterize localization of $\beta$ III spectrin in dendritic protrusions, we took advantage of cultured hippocampal neurons that are a far better system for high-resolution imaging. Fluorescence microscopy of 17-21 DIV hippocampal neurons costained with $\beta$ III spectrin antibody and fluorescently labeled phalloidin (Fig. $2 A, B$ ) showed that $\beta$ III spectrin was localized along the dendrite shafts, but also in a fraction of actin-rich dendritic protrusions with a strong preference toward dendritic spines relative to dendritic filopodia (Fig. $2 A-C$ ). Thus, the majority $(\sim 80 \%)$ of dendritic spines at $14-21$ DIV was stained with $\beta$ III spectrin antibody, but only a small fraction $(\sim 20 \%)$ of dendritic filopodia in 7 DIV neurons exhibited a detectable $\beta$ III spectrin signal (Fig. $2 C$ ).
Importantly, $\beta$ III spectrin in dendritic spines was rarely detected in the spine head and was not abundant there when detected (Fig. $2 A, B)$. On the other hand, $\beta$ III spectrin staining at the spine bases and necks was typically brighter than in the adjacent dendrite shaft, suggesting specific enrichment of $\beta$ III spectrin at the spine necks and bases, but not in their heads. Quantification of subspine distribution of $\beta$ III spectrin (Fig. $2 G$ ) showed that $81 \%$ of dendritic spines in 17 DIV hippocampal neurons were characterized by dendriteproximal localization of $\beta$ III spectrin, when the $\beta$ III spectrin signal was maximal at the base and tapered off before reaching the tip of the head, whereas the remaining spines showed a bimodal distribution of $\beta$ III spectrin featuring a second lower intensity peak of the $\beta$ III spectrin staining in the spine head. The $\beta$ III spectrin signal in spine 


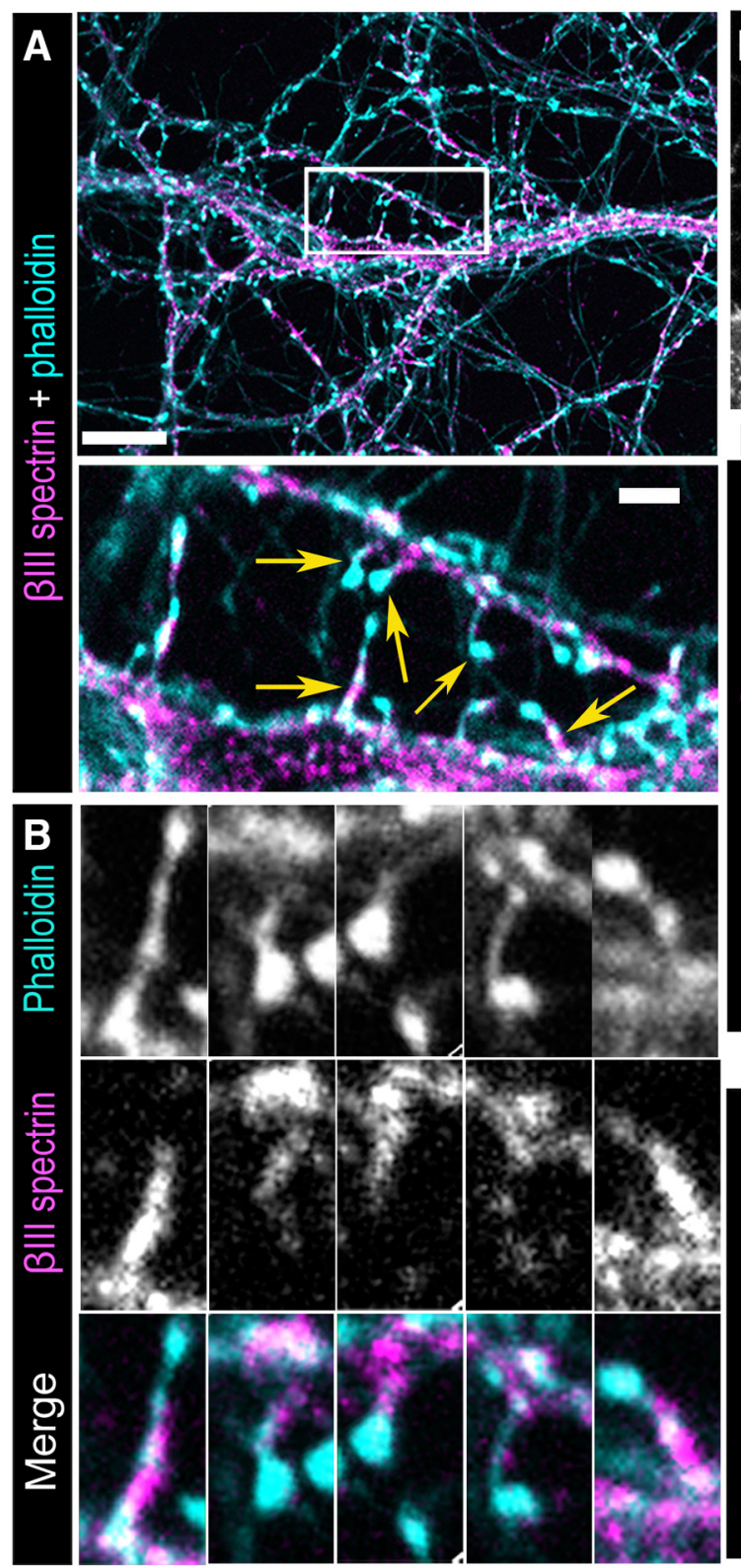

C

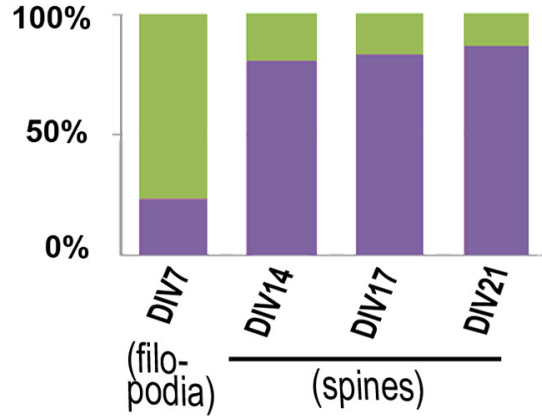

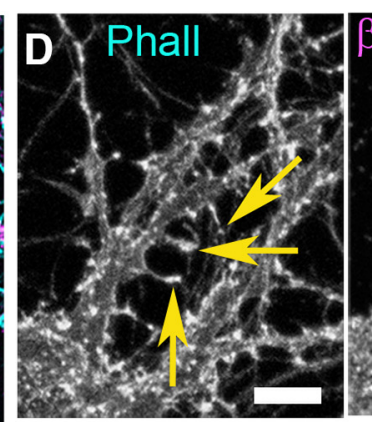
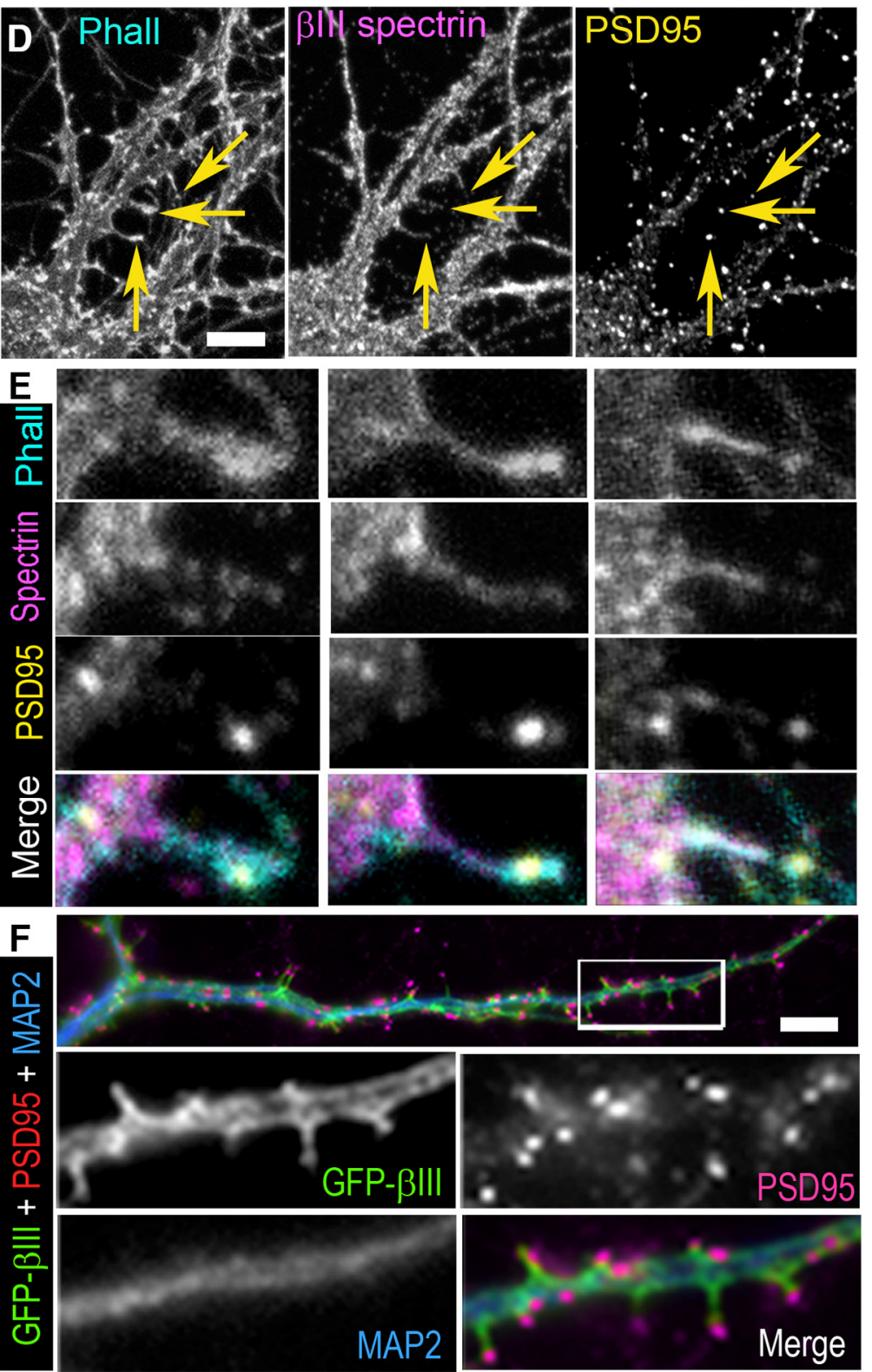

G
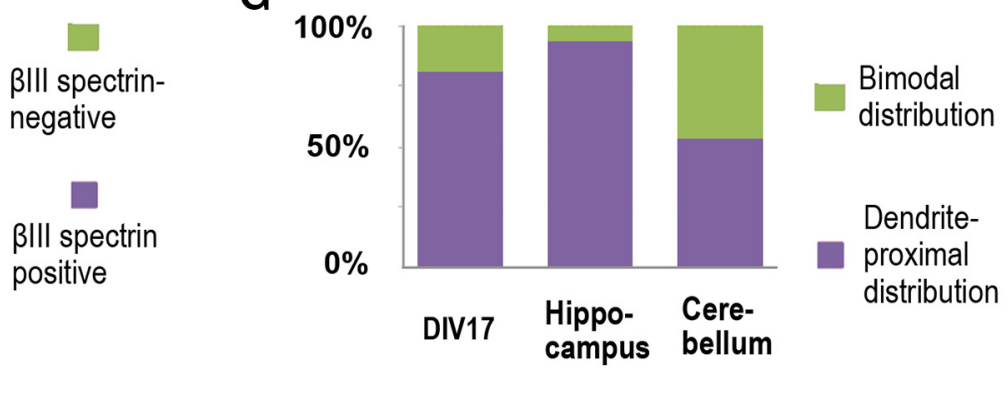

Figure 2. $\quad \beta I I I$ spectrin is enriched in the neck and base of dendritic spines. $A$, Staining of 17 DIV hippocampal neurons with $\beta$ III spectrin antibody (magenta) and phalloidin (cyan) shows that $\beta$ III spectrin is enriched at dendritic spine bases and necks, but not abundant in spine heads. Top, Boxed region is enlarged in the bottom. Scale bars: Top, $10 \mu \mathrm{m}$; Bottom, $2 \mu \mathrm{m}$. $\boldsymbol{B}$, Enlarged views of dendritic spines marked by arrows in $\boldsymbol{A}$ (bottom). C, Percentage of $\beta \mathrm{III}$ spectrin-positive dendritic protrusions in neurons of different ages (7 DIV: $N=128$ dendritic protrusions in 9 cells; 14 DIV: $N=$ 124 protrusions in 6 cells; 17 DIV: $N=100$ protrusions in 9 cells; 21 DIV: $N=119$ protrusions in 10 cells). $D$, Staining of 14 DIV hippocampal neurons with phalloidin and antibodies against $\beta$ III spectrin and PSD95. Scale bar, $5 \mu \mathrm{m}$. $\boldsymbol{E}$, Enlarged views of dendritic spines marked by arrows in $\boldsymbol{D}$. $\boldsymbol{F}$, Expression of GFP- $\beta$ III spectrin in 14 DIV hippocampal neurons followed by staining with antibodies to GFP (green), MAP2 (blue), and PSD95 (magenta). Top, Merged image of a dendrite. Boxed area is zoomed below as individual channels and a merged image. Scale bar, $5 \mu \mathrm{m}$. G, Quantification of subspine distribution of $\beta$ III spectrin in 17 DIV cultured rat hippocampal neurons (208 spines from 9 dendrite segments) and tissue sections from mouse hippocampus (74 spines from 18 dendrite segments) and cerebellum (126 spines from 18 dendrite segments). 
heads was largely detergent-sensitive, in contrast to the $\beta$ III spectrin populations in dendrites and spine necks.

To directly evaluate $\beta$ III spectrin localization relative to the PSD, we stained F-actin, $\beta$ III spectrin, and a PSD marker, PSD95 (Fig. $2 D, E$ ) in neurons. These data showed no significant colocalization between $\beta$ III spectrin, which was enriched in spine necks and bases, and PSD95, which was restricted to F-actin-rich spine heads. Similar results were obtained with ectopically expressed GFP- $\beta$ III spectrin (Fig. $2 F$ ) and by immunofluorescence staining of cultured rat cortical neurons (data not shown).

\section{$\beta$ III spectrin is localized in dendrite-proximal regions of dendritic spines in the brain tissue}

Enrichment of $\beta$ III spectrin at the spine necks and bases in cultured hippocampal and cortical neurons and its negligible presence in the vicinity of the PSD in spine heads is surprising because $\beta$ III spectrin is thought to stabilize the postsynaptic transmembrane proteins at the synapse (Jackson et al., 2001; Ikeda et al., 2006; Armbrust et al., 2014). Therefore, we also determined the subspine distribution of $\beta$ III spectrin in the mouse brain tissue. Immunofluorescence confocal microscopy of tissue sections from the hippocampus (Fig. $3 A$ ) and the cerebellum (Fig. 3B) demonstrated that $93 \%$ of spines in the hippocampus and $53 \%$ of spines in the cerebellum exhibited dendrite-proximal localization of $\beta$ III spectrin (Fig. $2 G$ ).

To determine $\beta$ III spectrin localization in dendritic spines at higher resolution, we performed EM of thin sections from mouse brain tissue after immunogold staining of $\beta$ III spectrin (Fig. $3 C$ ). Synapses in thin sections were identified by accumulation of synaptic vesicles on the presynaptic side and by the presence of the PSD on the postsynaptic side. Specificity of staining was reflected by the presence of gold particles in some processes (putative dendrites), but not in myelinated axons or within presynaptic boutons. For most synapses, as expected, only the head of the spine was captured in the section. The majority of these isolated spine heads were unlabeled, but some heads contained gold particles, which were located at a distance from the PSD. When an entire spine with the neck, base, and a part of the dendrite were found in the sections, $\beta$ III spectrin immunogold particles were readily apparent in the dendrite, the spine base, and the neck and, occasionally, in the head. Notably, we never observed gold particles overlapping with the PSD. Measurements of the shortest distances between individual gold particles and the postsynaptic membrane yielded an average value of $416 \pm 260 \mathrm{~nm}$ (mean \pm SD; $N=42$ spines and 196 gold particles), which was much greater than the average thickness of the PSD $(62 \pm 19 \mathrm{~nm} ; N=$ 42 PSDs). These data suggest that, even when $\beta$ III spectrin is present in the spine head, it is not associated with the PSD or the postsynaptic membrane.

Together, we found that $\beta$ III spectrin localizes primarily at the base and neck of dendritic spines, suggesting an important role of $\beta$ III spectrin in basal regions of dendritic spines.

\section{$\beta \mathrm{III}$ spectrin is a part of the cytoskeletal network characteristic specifically for the base and neck of dendritic spines}

Dendrite-proximal location of $\beta$ III spectrin in dendritic spines suggests that $\beta$ III spectrin may play a structural role in the spine neck and base. A primary determinant of the dendritic spine shape is thought to be the actin cytoskeleton. Dense branched actin filament networks expand and maintain the bulbous shape of the dendritic spine head (Kim et al., 2006; Wegner et al., 2008; Hotulainen et al., 2009; Spence et al., 2016), whereas sparser actin networks are present in the spine neck and base (Korobova and
Svitkina, 2010). Accumulation of $\beta$ III spectrin at the basal compartments of dendritic spines revealed by light microscopy suggests that spectrin and actin may cooperate for shaping the spine.

Spectrin $\alpha / \beta$ tetramers are thin elongated molecules with a physiological length of 60-200 $\mathrm{nm}$ depending on the degree of extension (Brown et al., 2015). We used PREM to morphologically detect $\beta$ III spectrin in the dendritic spine cytoskeleton and reveal its spatial organization at high resolution. To improve visualization of spectrin molecules among abundant actin filaments, we labeled actin filaments in dendritic spines with myosin subfragment 1 (S1). In these samples, actin filaments become thicker and have characteristic ragged contours. We found that heads of dendritic spines were filled with a dense network of S1-decorated actin filaments (Fig. 4A). In contrast, the neck and base of dendritic spines, as well as spine-proximal dendrite regions, contained abundant undecorated thin fibrils (Fig. 4A-C) that were occasionally seen to form a fine net (Fig. $4 B$ ). These fibrils $(7 \pm 1 \mathrm{~nm}$ in thickness, mean $\pm \mathrm{SD}$; all PREM-derived dimensions include 3-4 $\mathrm{nm}$ of platinum coating) were clearly distinct from $30 \pm 2 \mathrm{~nm}$ thick smoothly contoured microtubules and $16 \pm 2 \mathrm{~nm}$ thick S1-decorated actin filaments. Thus, the base and the neck of dendritic spines are enriched in fibrils that resemble spectrin molecules by their appearance. A similar observation was made more than three decades ago (Landis and Reese, 1983), but these fibrils remained unidentified. Spine bases also contained thick nonactin filaments with rough outlines, which could correspond to septin filaments based on their shape (Ong et al., 2014) and location at the dendritic spine base (Tada et al., 2007; Xie et al., 2007). Using immunogold PREM, we indeed detected septin 7 at spine bases, as well as at their junctions with axons (Fig. 4E).

To test whether the nonactin thin fibrils in dendritic spines correspond to $\beta$ III spectrin molecules, we used immunogold PREM with $\beta$ III spectrin antibody of 17 DIV neurons (Fig. 4D). After detergent extraction, $\beta$ III spectrin did not change its typical distribution and remained associated with the detergentinsoluble neuronal cytoskeleton. Consistent with the light microscopy data (Fig. 2), immuno-PREM revealed a polarized distribution of $\beta$ III spectrin in dendritic spines (Fig. $4 D$ ). Specifically, $\beta$ III spectrin immunogold particles were enriched in the basal part of spine necks, spine bases, and adjacent sections of parent dendrites, whereas the spine heads and the distal parts of spine necks had significantly lower levels of labeling. Dendrite shafts away from the spine base were also labeled but at a lower density compared with regions near spine bases. High-resolution images of the less crowded areas showed that $\beta$ III spectrin immunogold particles associated with thin $(\sim 7 \mathrm{~nm})$ fibrils (Fig. $4 D$, top, inset), supporting the idea that these thin fibrils correspond to $\beta$ III spectrin-containing molecules. These data show that $\beta$ III spectrin is a component of the basal cytoskeleton of dendritic spines, and thus likely cooperates with other cytoskeletal elements for supporting the shape of these spine regions.

\section{$\beta$ III spectrin is essential for the formation of dendritic spines and accumulation of PSD95}

We next investigated a role of $\beta$ III spectrin in dendritic spine formation by silencing endogenous $\beta$ III spectrin. Hippocampal neurons were infected at 11 DIV with lentiviral vectors expressing shRNA and Cerulean fluorescent protein and examined $6 \mathrm{~d}$ later at 17 DIV (Fig. 5). Western blot analysis showed that $\beta$ III spectrin expression in neurons transfected with each of the two different $\beta$ III spectrin-targeting shRNAs was decreased by $\sim 80 \%$, compared with neurons transfected with a nontargeting shRNA (Fig. 5A). 
A
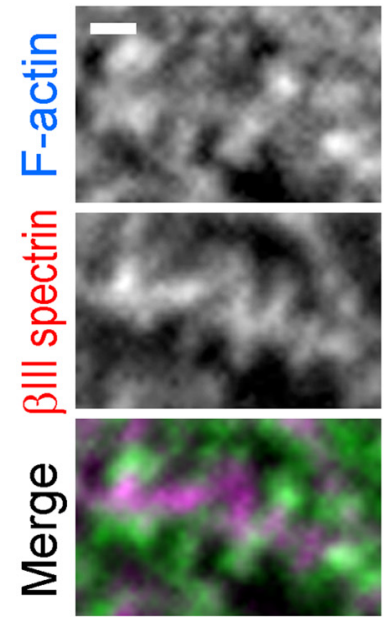
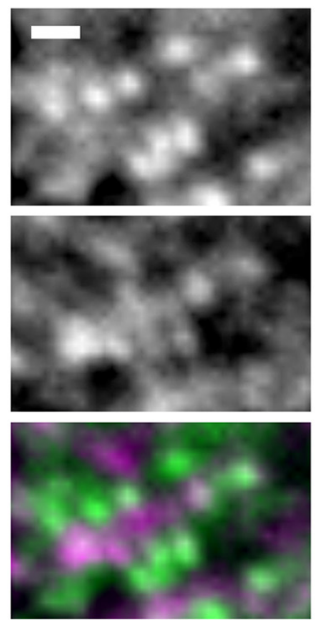
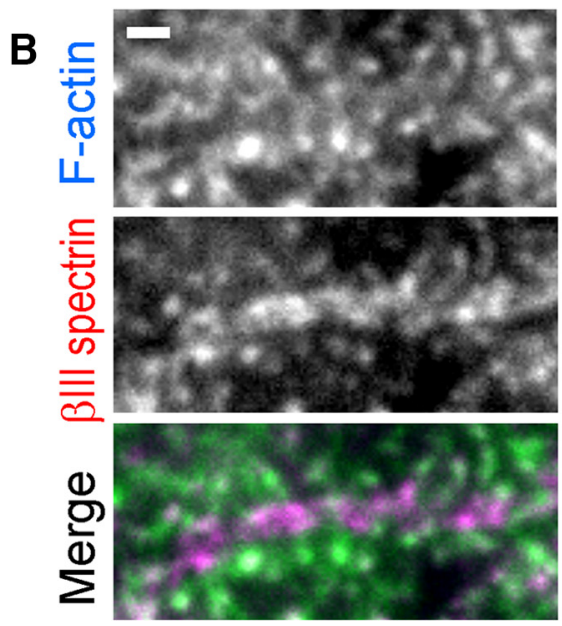

c
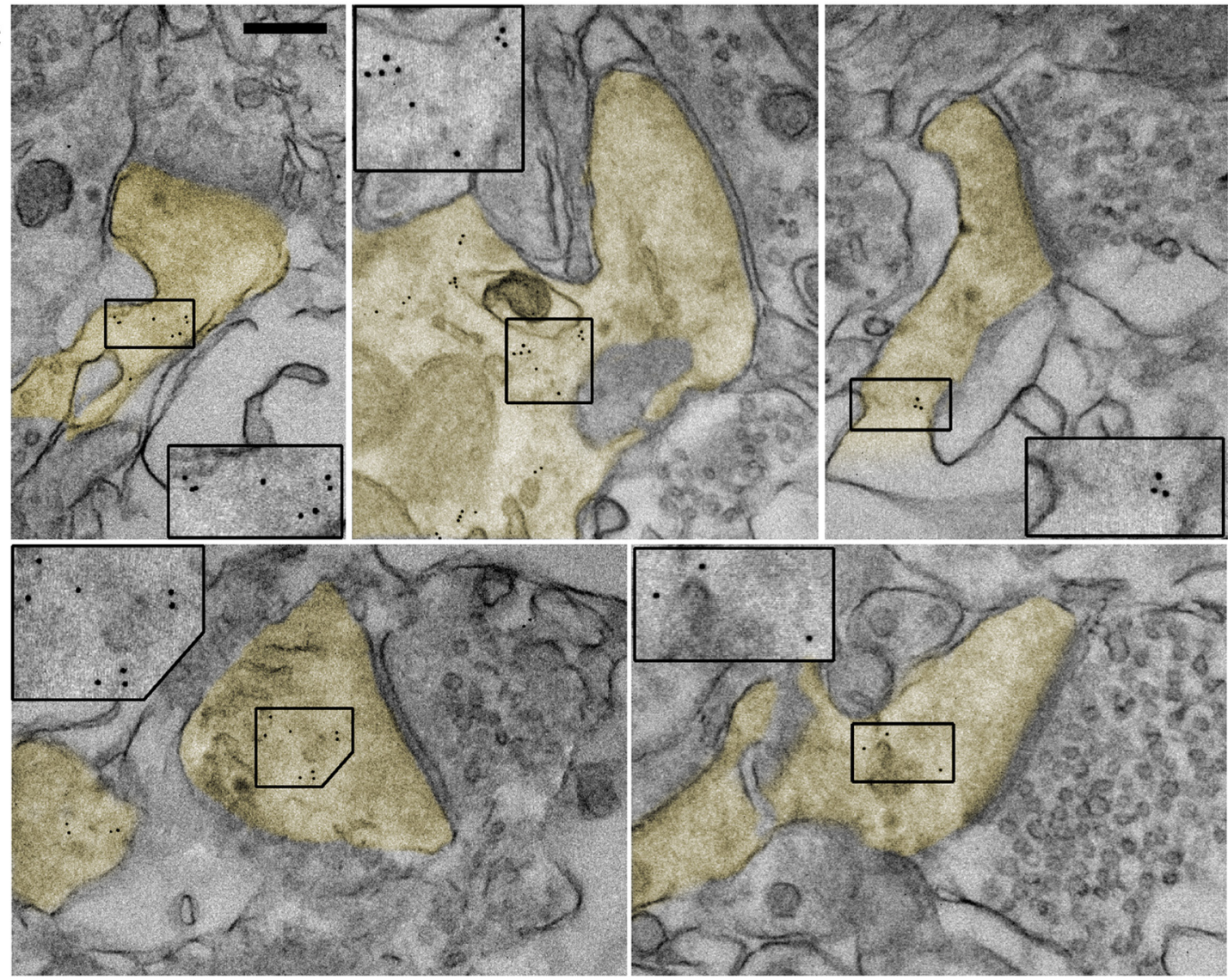

Figure 3. Subspine distribution of $\beta$ III spectrin in brain tissue. $\boldsymbol{A}, \boldsymbol{B}$, Fluorescence staining with $\beta$ III spectrin antibody (magenta) and phalloidin (cyan) of tissue sections from mouse hippocampus $(\boldsymbol{A})$ and cerebellum (B).C, Immunogold EM of $\beta$ III spectrin staining in thin sections of mouse brain. Dendritic spines are pseudocolored in yellow. Insets, Boxed regions are enlarged to show gold particles $(5 \mathrm{~nm})$. Synaptic vesicles can be seen on the opposite side of the synapses. Scale bars: $A, B, 1 \mu \mathrm{m} ; C, 200 \mathrm{~nm}$.

Staining of 17 DIV cultures with phalloidin revealed a significant reduction in the density of dendritic spines in neurons transfected with $\beta$ III spectrin-targeting shRNAs, compared with cells transfected with control shRNA (Fig. 5B,C). Because dendritic spines are principal sites of $\mathrm{F}$-actin accumulation in mature neurons, the overall intensity of phalloidin staining of neuronal cultures was also reduced after $\beta$ III spectrin knockdown. Reduced spine densities were also observed in $\beta$ III spectrindeficient Purkinje neurons in the cerebellum (Stankewich et al., 2010; Gao et al., 2011). We also noted a minor simplification of the dendritic tree in these conditions, so that the number of primary and secondary dendrites extending from the neuron body was reduced by $10 \%-20 \%$ (data not shown). This phenotype in hippocampal neurons is consistent with the previously reported dendritic atrophy in $\beta$ III spectrin-deficient Purkinje neurons (Ikeda et al., 2006; Perkins et al., 2010; Gao et al., 2011). However, relatively minor effect of $\beta$ III spectrin knockdown on dendrite formation in our experimental conditions suggests that the deficient formation of dendritic spines is a direct effect of $\beta$ III spectrin knockdown rather than a secondary effect of impaired dendrite development. Inhibition of dendritic spine formation after knockdown of $\beta$ III spectrin was also observed in cultured cortical neurons (data not shown). These data show that $\beta$ III spectrin is specifically re- 

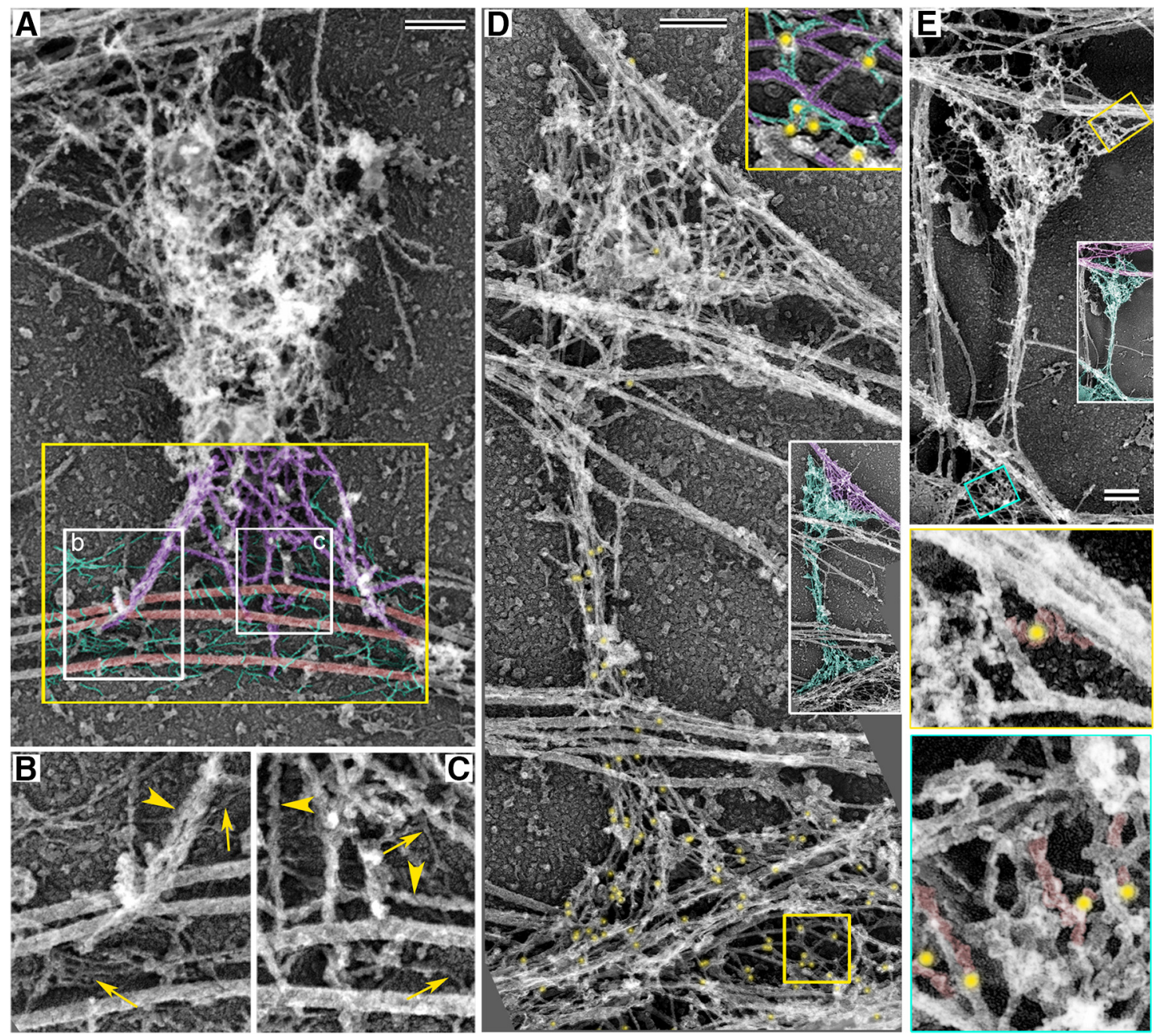

Figure 4. PREM of dendritic spine cytoskeleton in 17 DIV hippocampal neurons. $A-C$, Nonactin filamentous components in the dendritic spine cytoskeleton. $A$, Dendritic spine with actin filaments decorated by myosin S1. Cytoskeletal components within the yellow box at the spine base are pseudocolored as the following: purple represents S1-decorated actin filaments; red represents microtubules; green represents undecorated thin fibrils. $\boldsymbol{B}, \boldsymbol{C}$, Enlarged white boxes ( $b$ and c, respectively) from $\boldsymbol{A}$ showing $\mathrm{S1}$-decorated actin filaments (arrowheads) and undecorated thin fibrils (arrows). B, Bottom left arrow indicates a fine network of undecorated thin fibrils. D, Dendritic spine labeled by $\beta$ III spectrin immunogold. Gold particles ( $12 \mathrm{~nm}$, pseudocolored in yellow) label the spine base and neck but are sparse in the spine head. White-framed inset, Color-coded version of the same image showing the dendritic spine in cyan and axon in magenta. Yellow box is enlarged in the yellow-framed inset and color-coded to show gold particles (yellow), actin filaments (purple), and spectrin molecules (green). $\boldsymbol{E}$, Immunogold PREM with septin 7 antibody. Top, Overview of a dendritic spine. Inset, Color-coded version of the same image showing the dendrite and dendritic spine in cyan and axon in magenta. Middle, Bottom, Enlarged areas outlined by yellow and blue boxes in the top panel. Gold particles ( $18 \mathrm{~nm}$, pseudocolored in yellow) associate with rough-contoured filaments (pseudocolored in red) at the spine base (bottom) and in a putative presynaptic compartment of the axon (middle). Scale bars, $200 \mathrm{~nm}$.

quired for the formation and/or maintenance of dendritic spines in mature neurons.

\section{$\beta$ III spectrin is required for normal accumulation of PSD95 at synapses}

PSD95 is a key scaffolding protein that accumulates within PSD in dendritic spine heads. We evaluated the distribution of PSD95 in $\beta$ III spectrin-depleted neurons relative to control neurons infected with nontargeting shRNAs. We found that the reduction in the dendritic spine density resulting from the $\beta$ III spectrin knockdown was accompanied by a significant loss of bright and normally sized PSD95-positive clusters (Fig. 5D,E). Interestingly, the remaining bright PSD95 puncta were often located on the shaft of the dendrite rather than at the tip of a spine (Fig. $5 D, F)$. Notably, in addition to remaining bright PSD95 accumulations, many small and faint PSD95 puncta were detectable in dendrites of $\beta$ III spectrin-depleted neurons. Such faint PSD95 puncta could also be seen in dendrites of control neurons.
These data suggest that $\beta$ III spectrin is required for the formation and/or maintenance of PSD integrity in mature neurons. Notably, other postsynaptic components, such as glutamate transporter EAAT4 and glutamate receptors mGluR1 $\alpha$ and GluR $\delta 2$, were found to be partially lost from synaptosomal fractions from SCA5 tissues compared with normal tissues (Jackson et al., 2001; Ikeda et al., 2006; Armbrust et al., 2014), suggesting a common $\beta$ III spectrin-dependent mechanism of retention of these molecules at the synapse.

\section{Depletion of $\beta$ III spectrin does not inhibit formation of the} presynaptic boutons

Synapse formation typically involves coordinated development of presynaptic and postsynaptic molecular complexes, so that interference with postsynaptic functions often leads to aberrations in presynaptic boutons (Sala and Segal, 2014). Therefore, we tested whether $\beta$ III spectrin depletion affects presynaptic structures in neurons. Triple fluorescence staining of control 17 
A

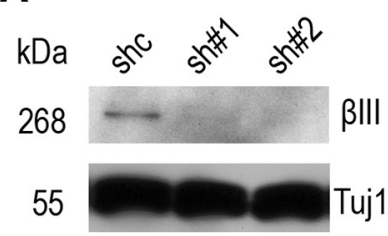

C

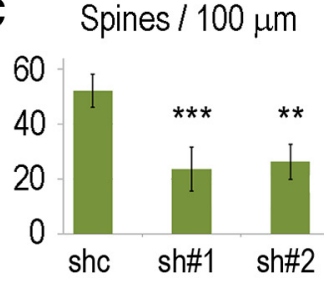

$\mathbf{E}$

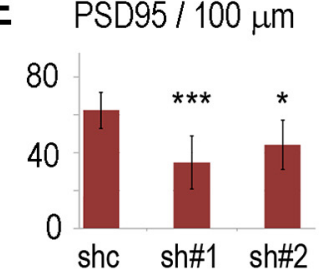

F $\%$ of PSD on spines

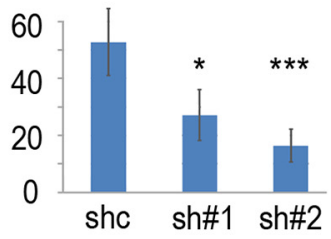

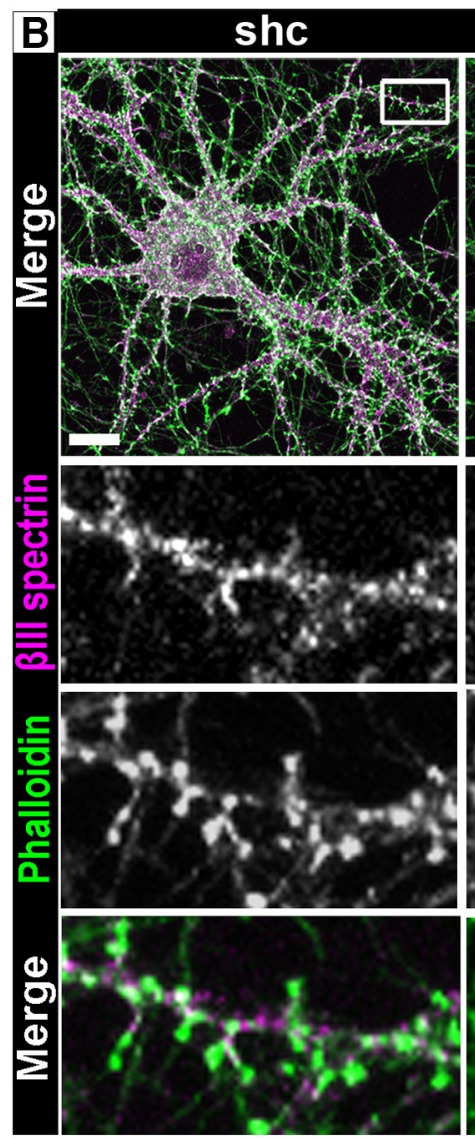
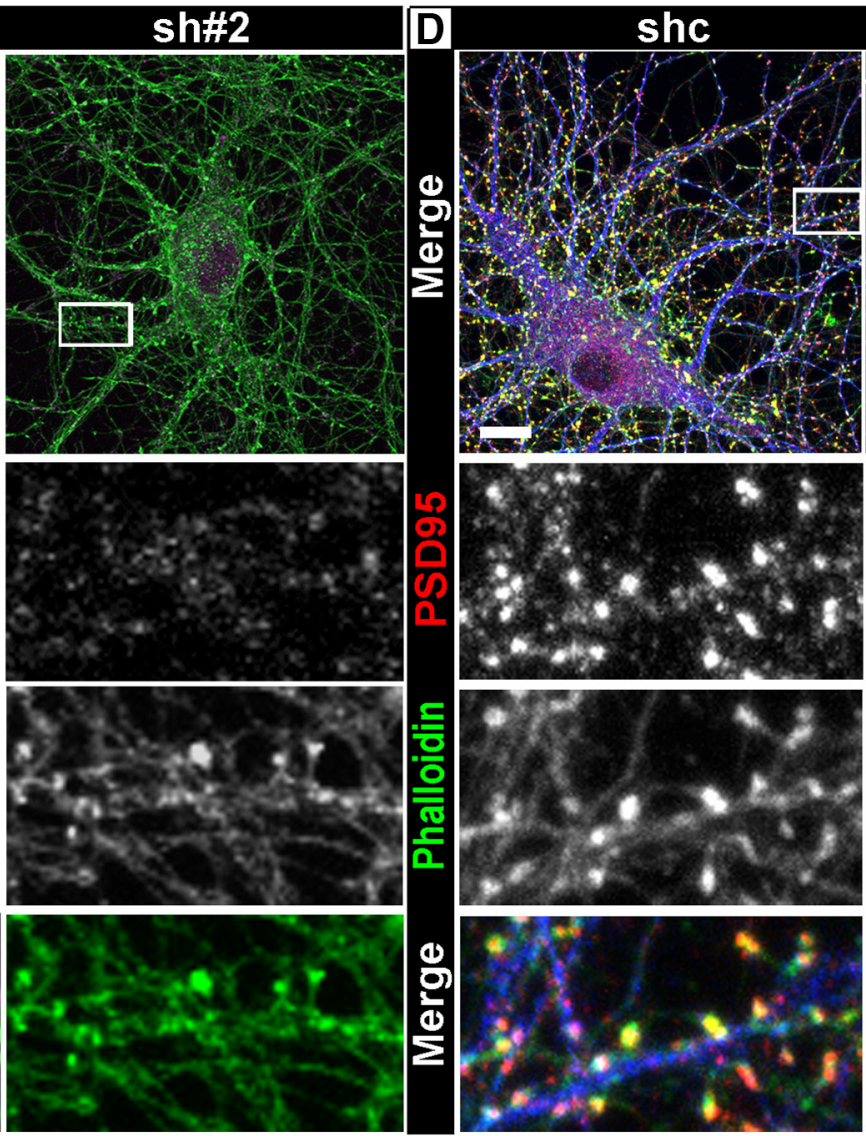

sh\#2
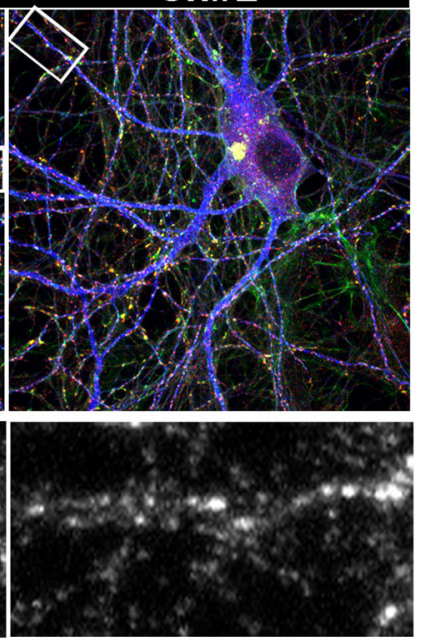

Figure 5. Loss of $\beta$ III spectrin functions inhibits formation of dendritic spines. $A$, Western blotting of $\beta$ III spectrin in lysates of $17 \mathrm{DIV}$ neurons transfected with control (shc) or $\beta$ III spectrintargeting shRNAs (sh\#1 and sh\#2). Tubulin $\beta 3$ (Tuj1) is used as loading control. B, Fluorescence staining of 17 DIV neurons transfected with control shRNA (shc, left) or $\beta$ III spectrin shRNA\#2 (sh\#2, right) with phalloidin (green) and $\beta$ III spectrin antibody (magenta). Scale bar, $10 \mu \mathrm{m}$. Top, Boxed areas are enlarged at bottom. C, Average number of dendritic spines per $100 \mu \mathrm{m}$ of MAP2-labeled dendrites in neurons infected with control (shc) or $\beta$ Ill spectrin (sh\#1 and sh\#2) shRNAs (shc: $N=651$ spines in 9 cells; sh\#1: $N=199$ spines in 9 cells; sh\#2: $N=169$ spines in 10 cells). Error bars indicate SD. ${ }^{* * *} p=0.00013$ (Dunn's Multiple Comparisons Test). ${ }^{* *} p=0.0013$ (Dunn's Multiple Comparisons Test). D, Fluorescence staining of 17 DIV neurons transfected with control shRNA (shc, left) or $\beta$ III spectrin shRNA\#2 (sh\#2, right) with phalloidin (green), MAP2 (blue), and PSD95 antibody (red). Scale bar, $10 \mu \mathrm{m}$. Top, Boxed areas are enlarged at bottom. E, Average number of PSD95 clusters per $100 \mu \mathrm{m}$ of MAP2-labeled dendrites (shc: $N=1261$ clusters in 9 cells; sh\#1: $N=199$ clusters in 9 cells; sh\#2: $N=443$ clusters in 10 cells) in neurons transfected with control (shc) or $\beta$ III spectrin (sh\#1 and sh\#2) shRNAs. Error bars indicate SD. ${ }^{* * *} p=0.0014$ (Dunn's Multiple Comparisons Test). ${ }^{*} p=0.046$ (Dunn's Multiple Comparisons Test). $\boldsymbol{F}$, Average percentage of PSD95 clusters associated with dendritic spines versus dendrite shafts (shc: $N=1155$ clusters in 9 cells; sh\#1: $N=961$ clusters in 8 cells; sh\#2: $N=1791$ clusters in 10 cells). Error bars indicate SD. ${ }^{* * *} p=$ 0.000012 (Dunn's Multiple Comparisons Test). * $p=0.014$ (Dunn's Multiple Comparisons Test).

DIV neurons with phalloidin, synapsin I antibody (presynaptic marker), and an axonal marker SMI312 revealed actin-rich dendritic spines that extended from dendrites and made contacts with synapsin I-rich puncta on axons (Fig. 6A, B). Some synapsin I puncta, probably corresponding to shaft synapses, were located on dendritic shafts. Additionally, axons contained low-intensity synapsin I puncta that did not obviously associate with dendrites. They could correspond to "orphan" boutons or traveling "packets" of presynaptic components, which are thought to serve as precursors of presynaptic boutons (McAllister, 2007).

In 17 DIV neurons transfected with $\beta$ III spectrin shRNAs, the number of synapsin I-positive puncta did not change compared with cells transfected with control shRNA (Fig. 6A,C), despite significant inhibition of dendritic spines. Accordingly, only a small fraction of synapsin I puncta were associated with remaining dendritic spines, whereas the majority of them were found either on dendritic shafts or in axons away from detectable dendrites (Fig. $6 A, B, E$ ). Similar results were obtained using an alternative presynaptic marker, synaptophysin (data not shown).

Double immunofluorescence staining of postsynaptic (PSD95) and presynaptic (synapsin I) markers (Fig. 6D) showed that control neurons contained numerous juxtaposed bright puncta of PSD95 and synapsin I, a signature of synapses. A few weak synapsin I puncta not apposed by PSD95 signals were also present. In contrast, in $\beta$ III spectrin knockdown neurons, even bright synapsin I puncta were often associated with small and faint PSD95 puncta or not associated with a detectable PSD95 signal (Fig. $6 D, E)$. These data suggested that $\beta$ III spectrin knockdown may 

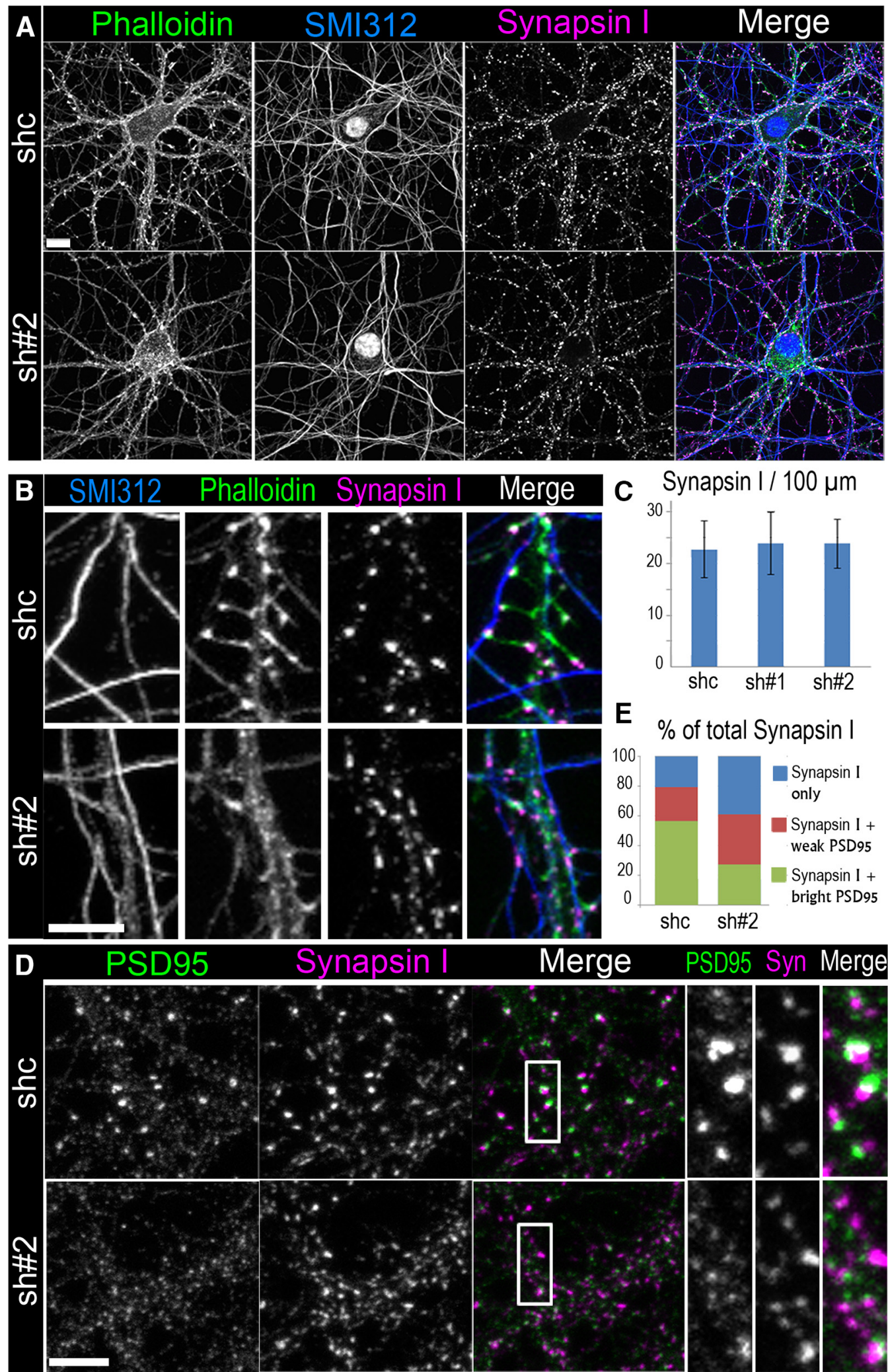

Figure 6. Depletion of $\beta$ III spectrin results in formation of aberrant synapses. $A, B$, Fluorescence staining of 17 DIV neurons transfected with control shRNA (shc) or $\beta$ III spectrin shRNA (sh\#2) with phalloidin, axonal marker SMI312, and synapsin I antibody. Scale bar, $10 \mu \mathrm{m}$. B, High-magnification images showing spiny synapses in a control cell (top) and shaft synapses in a $\beta$ III spectrindepleted cell (bottom). Scale bar, $5 \mu \mathrm{m}$. C, Average numbers of synapsin I puncta per $100 \mu \mathrm{m}$ of axon length (shc: $N=664$ puncta in 9 cells; sh\#1: $N=631$ puncta in 10 cells; sh\#2: $N=615$ puncta in 10 cells). Error bars indicate SD. D, Staining of PSD95 and synapsin I in control (shc) and $\beta$ III spectrin-depleted (sh\#2) cells. Scale bar, $5 \mu \mathrm{m}$. Boxed areas are zoomed at right. E, Quantification of synapsin I puncta associated with "bright" or "weak" PSD95 puncta or not associating with PSD95 puncta ("synapsin I only") in control and $\beta$ III spectrin-depleted cells (shc, N = 694 puncta in 5 cells; sh\#2,N=578 puncta in 5 cells). 
favor formation of shaft synapses with low abundance of PSD95 at the expense of normal spiny synapses enriched with PSD95.

\section{Presynaptic components in $\beta$ III spectrin-depleted neurons form shaft synapses or nonsynaptic structures}

To reach more definite conclusions regarding synapse morphology in control and $\beta$ III spectrin-depleted neurons, we used PREM of directly fixed (nonextracted) cells that largely retain their plasma membrane, although the membrane became perforated in some neurites. Mushroom-shaped dendritic spines could be readily recognized in control neurons by their shape (Fig. 7A). However, other typical spine morphologies, such as thin and stubby spines, were also present in these cultures. Because precise dimensions of dendritic spines are of much interest in the field, we measured several parameters of spine morphology in PREM samples of 17 DIV neurons. The average length of dendritic spines was found to be $1.72 \pm 0.89 \mu \mathrm{m}$ (mean $\pm \mathrm{SD} ; N=73$ spines); the average width of the spine head was $0.68 \pm 0.38 \mu \mathrm{m}$; the average width of the spine base was $1.04 \pm 0.38 \mu \mathrm{m}$; and the average thickness of the spine neck at its narrowest point was $0.31 \pm 0.27 \mu \mathrm{m}$. The median values for the first three parameters were close to their means $(1.52,0.65$, and $1.03 \mu \mathrm{m}$, respectively), whereas the distribution of values for the thickness of the spine neck was skewed toward smaller thicknesses and had a median value of $0.20 \mu \mathrm{m}$, smaller than the mean $(0.31 \mu \mathrm{m})$.

The axonal regions that were in contact with spine heads usually exhibited a varicosity at the site of contact, as typical for presynaptic boutons (Fig. 7A). Similar varicosities, which did not make contacts with dendritic spines or anything else, were also occasionally observed along thin neurites, likely representing axons. In the cases where the plasma membrane of these axonal varicosities was ruptured, a collection of small vesicles could be seen inside (Fig. 7D), suggesting that they contain presynaptic vesicles or their precursors.

To confirm our interpretation of dendritic spine images, we performed correlative PREM of directly fixed samples that were fluorescently stained with phalloidin and synapsin I antibody and imaged by light microscopy before PREM processing (Fig. $7 B$ ). Spontaneous plasma membrane perforations in these samples were sufficient to allow penetration of fluorophore-labeled antibodies. When PREM and fluorescence images were overlaid, they showed that dendritic spine heads correlated with bright spots of phalloidin fluorescence, whereas axonal varicosities contacting the spine head overlapped with synapsin I immunofluorescence, confirming that they represent presynaptic boutons (Fig. 7B). We also found synapsin I-positive shaft synapses and nonsynaptic varicosities in these samples (data not shown).

As an alternative approach to identify presynaptic sites in PREM samples, we used immunogold labeling with a synaptophysin antibody. To allow for efficient penetration of immunogold particles, which are much larger than fluorophore-labeled antibodies, and at the same time preserve detergent-soluble presynaptic components, we permeabilized glutaraldehyde-fixed samples with a detergent before application of antibodies. This procedure produced multiple perforations in plasma membranes while keeping cell-cell boundaries detectable. In control 17 DIV neurons, presynaptic boutons labeled with the synaptophysin immunogold were mostly found in association with spine heads (Fig. 7C), but occasionally formed shaft synapses (data not shown) or existed as nonsynaptic axonal varicosities (Fig. 7E).

Using PREM analysis of directly fixed $\beta$ III spectrin knockdown neurons, we found very few examples of spines in these samples. Instead, we observed numerous examples of either lateral interactions between aligned neurites (Fig. $7 F$ ) or putative orphan presynaptic structures, in which clusters of vesicles were visible through spontaneous perforations of the plasma membrane (Fig. 7J). Synaptophysin immunogold labeling of $\beta$ III spectrin knockdown neurons revealed multiple presynaptic structures that either formed shaft synapses (Fig. 7G-I) or existed as orphan packets (Fig. $7 \mathrm{~K}$ ). The shape of the gold-labeled presynaptic structures in shaft synapses varied from round (Fig. 7I) to ellipsoid (Fig. $7 H$ ), possibly depending on the extent of cellcell interaction.

\section{Knockdown of $\boldsymbol{\beta}$ III spectrin increases amplitudes of miniature EPSCs (mEPSCs)}

Morphologically detectable loss of spines, either in physiological or experimental conditions, may be associated with disruption of synapses or a conversion from spiny to shaft synapses. These scenarios can be distinguished by measuring synaptic activity of neurons (Segal, 2010). We performed whole-cell patch-clamp recordings of mEPSCs in the presence of $1 \mu \mathrm{M}$ TTX, which eliminated action potentials. We found that the amplitude of mEPSCs was increased in $\beta$ III spectrin knockdown neurons, compared with control neurons (Fig. $8 A, B$ ), whereas the mEPSC frequencies were indistinguishable between the two groups (Fig. $8 A, C$ ). These data support increased formation of shaft synapses (Segal, 2010) after depletion of $\beta$ III spectrin in cultured hippocampal neurons, consistent with our morphological data obtained both by light microscopy and PREM.

\section{Discussion}

Our results provide an insight into several unresolved questions, which turned out to be related. First, we show that $\beta$ III spectrin plays a role in cell shape determination in nonerythroid cells. Second, we advance our knowledge about a cytoskeletal mechanism that can control the constricted shape of the dendritic spine neck. Third, we functionally test the proposed role of the spine neck as a diffusion barrier regulating synaptic function. Together, our results suggest a molecular mechanism of neurodegeneration in the SCA5 and SPARCA1 syndromes that so far remained obscure.

Spectrins are expressed in multiple cell types and perform various functions, such as formation of membrane domains with specific protein compositions, providing mechanical stability to cells, supporting intercellular adhesions, and forming diffusion barriers (for review, see Bennett and Lorenzo, 2016). A role of spectrins in cell shape determination is well established for erythrocytes but is limited for nonerythroid cells. Thus, it was demonstrated that the height of epithelial cells is decreased in the absence of $\beta$ II spectrin (Kizhatil et al., 2007). Our structural and functional data suggest that $\beta$ III spectrin plays an important role for forming a neck in mushroom-shaped dendritic spines, thereby extending the idea that spectrins are important players in cell shape determination to nonerythroid cells.

Our high-resolution analysis of $\beta$ III spectrin distribution shows that $\beta$ III spectrin is enriched at bases and necks of dendritic spines, but is not detectable in the PSD. A relatively weak $\beta$ III spectrin signal in spine heads is sensitive to detergent extraction, suggesting that it may be associated with some internal membrane compartments. In contrast, the actin- $\beta$ III spectrin network in dendrites and at the dendritic spine necks and bases resists detergent extraction, suggesting that it can play structural roles. Using PREM, we found that $\beta$ III spectrin-positive fibrils are present in the dendritic spine cytoskeleton and are especially numerous at the spine bases and necks. These fibrils likely correspond to indi- 

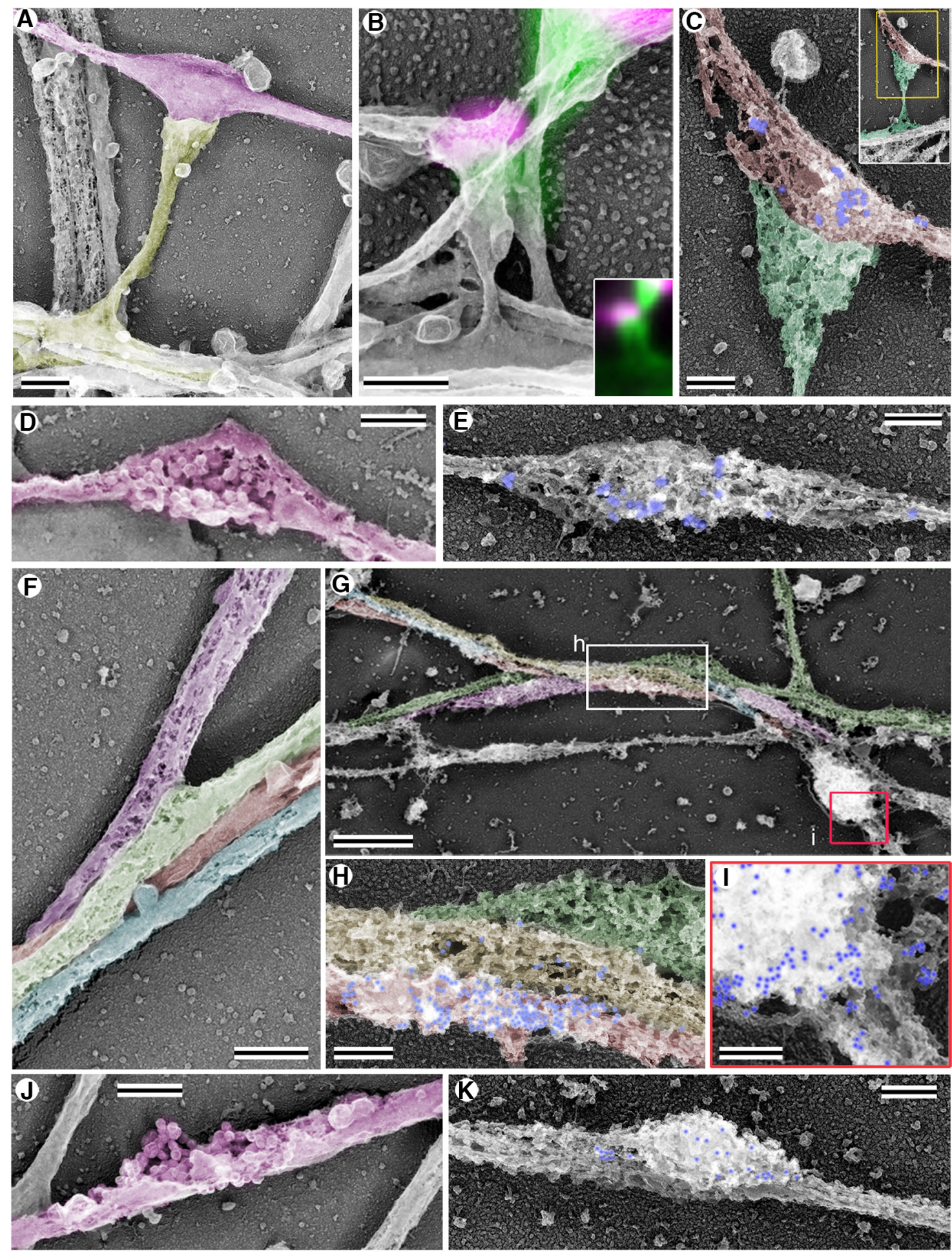

Figure 7. PREM of synapses in control and $\beta$ III spectrin knockdown neurons at 17 DIV. $A-E$, Neurons treated with control shRNA. $A$, Dendritic spine (yellow) forms a synapse with a presynaptic bouton in the axon (magenta) in nonextracted cells. $\boldsymbol{B}$, Correlative fluorescence microscopy and PREM of synapses formed on dendritic spines in neurons fluorescently stained with phalloidin (green) and synapsin I (magenta). Fluorescence image is superimposed onto the PREM image in the main panel and shown separately in the inset. C, Synaptophysin immunogold PREM of a dendritic spine (green) making a synapse with a presynaptic bouton (red) labeled with gold particles (pseudocolored in blue). Inset, Overview of the spine. D, Varicosity on a putative axon (magenta) of a control neuron with a collection of vesicles seen through spontaneous perforations of the plasma membrane; it likely corresponds to an orphan bouton. $E$, Unapposed presynaptic bouton in a control neuron revealed by synaptophysin immunogold PREM. Membranes are perforated due to detergent extraction after glutaraldehyde fixation. $\boldsymbol{F}-\boldsymbol{K}$, Neurons treated with $\beta$ III spectrin shRNA \#2. $\boldsymbol{F}$, A bundle of neurites making extensive lateral contacts in nonextracted cells (individual neurites are shaded in different colors). G-I, Synaptophysin immunogold PREM (gold particles pseudocolored in blue) of a bundle of neurites (shaded in different colors). Boxed regions are zoomed in $\boldsymbol{H}$ (white box) and $\boldsymbol{I}$ (red box). $\boldsymbol{H}$, Gold particles label an ellipsoid bouton in the putative axon (red-shaded neurite), which makes a shaft synapse with an adjacent putative dendrite. $I$, Gold-labeled globular varicosity on a putative axon. It may form a shaft synapse with the underlying "dendrite" or correspond to an orphan bouton. J, A putative orphan bouton (magenta) in nonextracted neuron; a collection of vesicles is seen through spontaneous perforations of the plasma membrane. $\boldsymbol{K}$, An orphan bouton revealed by synaptophysin immunogold PREM (gold particles pseudocolored in blue). Scale bars: $A, B, D, F, J, 0.5 \mu \mathrm{m} ; \boldsymbol{G}, 1 \mu \mathrm{m} ; \boldsymbol{C}, E, H, I, K, 0.2 \mu \mathrm{m}$. 

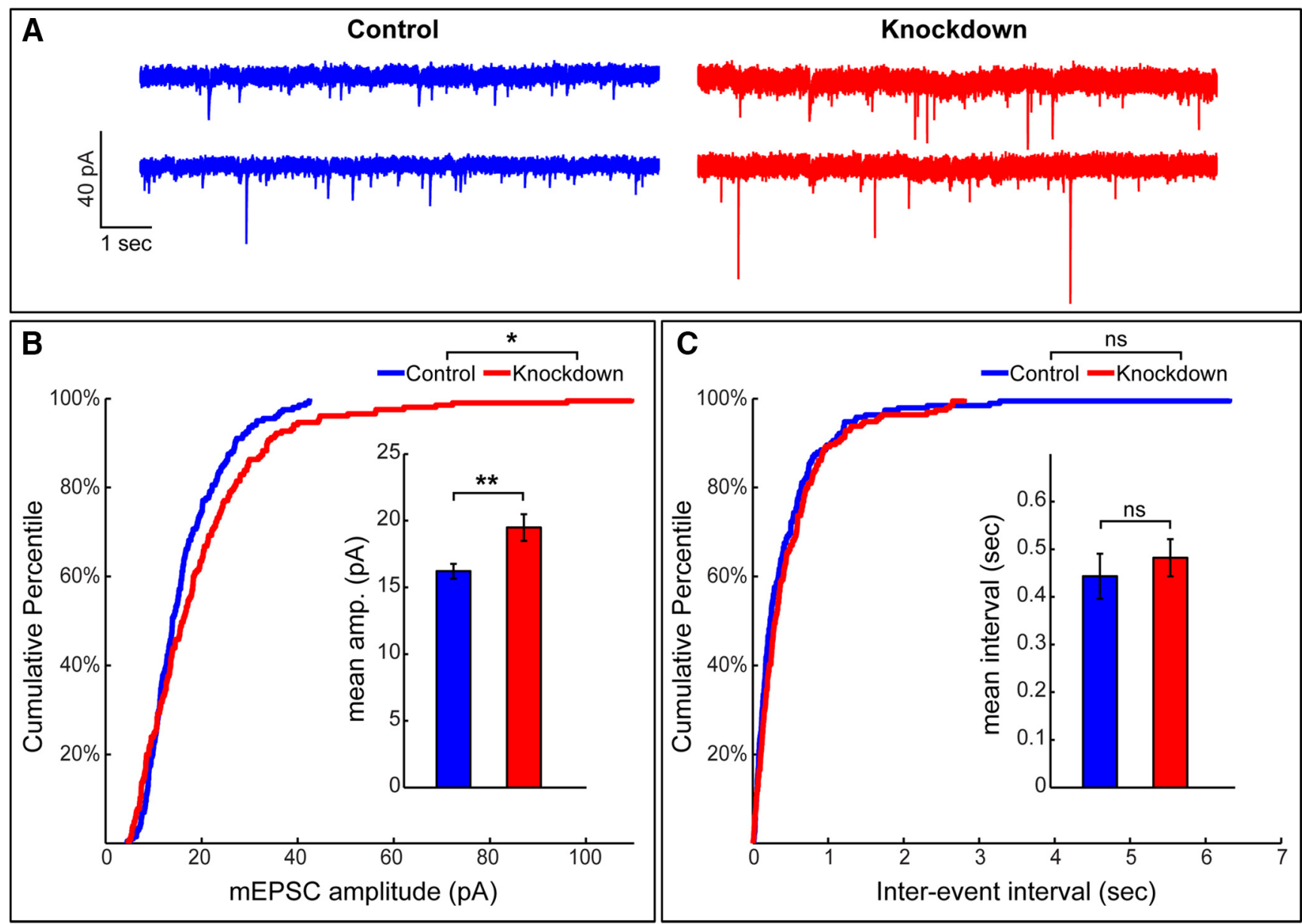

Figure 8. Knockdown of $\beta$ III spectrin increases amplitudes of spontaneous mEPSCs. $\boldsymbol{A}$, Representative $10 \mathrm{~s}$ traces of spontaneous mEPSCs in DIV17 transfected with $\beta$ III spectrin shRNA \#2 (knockdown) or a control shRNA (control). Whole-cell patch-clamp recordings were obtained under voltage-clamp configuration with a holding potential of - $70 \mathrm{mV}$. Each trace is from a different hippocampal neuron from the two experimental groups. $\boldsymbol{B}$, The distribution of mESPC amplitudes is shifted toward higher values. ${ }^{*} p=0.034$ (Kolmogorov-Smirnov test). The mean event amplitude is significantly higher in $\beta$ III spectrin knockdown neurons (19.48 $\pm 1.00 \mathrm{pA}, n=205$ events from 11 cells) compared with controls (16.21 $\pm 0.56 \mathrm{pA}, n=201$ events from 10 cells). ${ }^{* *} p=0.004$ (unpaired Student's $t$ test). C, The distribution of mEPSC interevent intervals ( $p=0.219$, Kolmogorov-Smirnov test) and the mean interevent interval is unchanged in $\beta$ III spectrin knockdown $(0.48 \pm 0.039 s)$ compared with control neurons $(0.44 \pm 0.047 s ; p=0.497$, unpaired Student's $t$ test).

vidual spectrin molecules. In some regions, organization of $\beta$ III spectrin-containing molecules resembles the fine network found in erythrocytes (Byers and Branton, 1985; Nans et al., 2011), but in most cases $\beta$ III spectrin appears to cross-link relatively long actin filaments rather than very short actin filaments characteristic for erythrocytes. Localization of $\beta$ II spectrin, a ubiquitous $\beta$ spectrin isoform (Bennett and Lorenzo, 2016), to a small subset of dendritic spines has also been reported (He et al., 2016; Sidenstein et al., 2016). In the nervous system, $\beta$ II spectrin primarily localizes to axons and is present at lower levels in dendrites. Functionally, $\beta \mathrm{II}$ spectrin has been shown to participate in the formation of the axon initial segment (Galiano et al., 2012) and nodes of Ranvier (Amor et al., 2017). No dendritic phenotypes arising from $\beta$ II spectrin deficiency have been reported so far, to our knowledge. However, these two $\beta$ spectrins may still cooperate in dendritic spines. Using PREM, we also detected septin 7 at the spine base, consistent with previously reported light microscopy data (Tada et al., 2007; Xie et al., 2007). Interestingly, perturbations of septin functions result in somewhat similar dendritic phenotypes (Tada et al., 2007; Xie et al., 2007; Yadav et al., 2017), suggesting that $\beta$ III spectrin and septins may also cooperate for shaping the spine neck.

Recent studies by subdiffraction fluorescence microscopy have revealed a periodic distribution of $\beta \mathrm{II}$ and $\beta \mathrm{IV}$ spectrins and
F-actin in axons, some dendrites (Xu et al., 2013; Zhong et al., 2014; D'Este et al., 2015; Leterrier et al., 2015; D'Este et al., 2016; He et al., 2016; Sidenstein et al., 2016), and even in dendritic spines (Bär et al., 2016). Periodicity of $\beta$ III spectrin was noted only in occasional small regions of dendrites (Zhong et al., 2014). Although with some imagination one can suppose a $\sim 200 \mathrm{~nm}$ periodicity of $\beta$ III spectrin immunogold distribution in the dendritic spine in Figure $4 D$, we so far were unable to reliably detect actin or $\beta \mathrm{IV}$ spectrin periodicity in neurons by immunogold PREM (Jones et al., 2014), possibly because of high complexity of PREM images compared with computationally simplified subdiffraction images. Nonetheless, it is hard to reconcile the reported F-actin periodicity in dendritic spine necks (Bär et al., 2016) with our PREM data, which consistently show that the entire length of the spine neck is occupied by a continuous actin filament network (see, e.g., Fig. 4). Furthermore, we previously showed that actin filament organization in dendritic spines observed by PREM closely matches the distribution of GFP-actin fluorescence in the same spines in living neurons (Korobova and Svitkina, 2010), suggesting that we neither lose nor gain actin filaments during sample preparation for PREM. Taking into account that actin cytoskeleton is particularly challenging for subdiffraction imaging and that not all drawbacks of these relatively new tech- 
Normal spectrin $\beta$ III functions

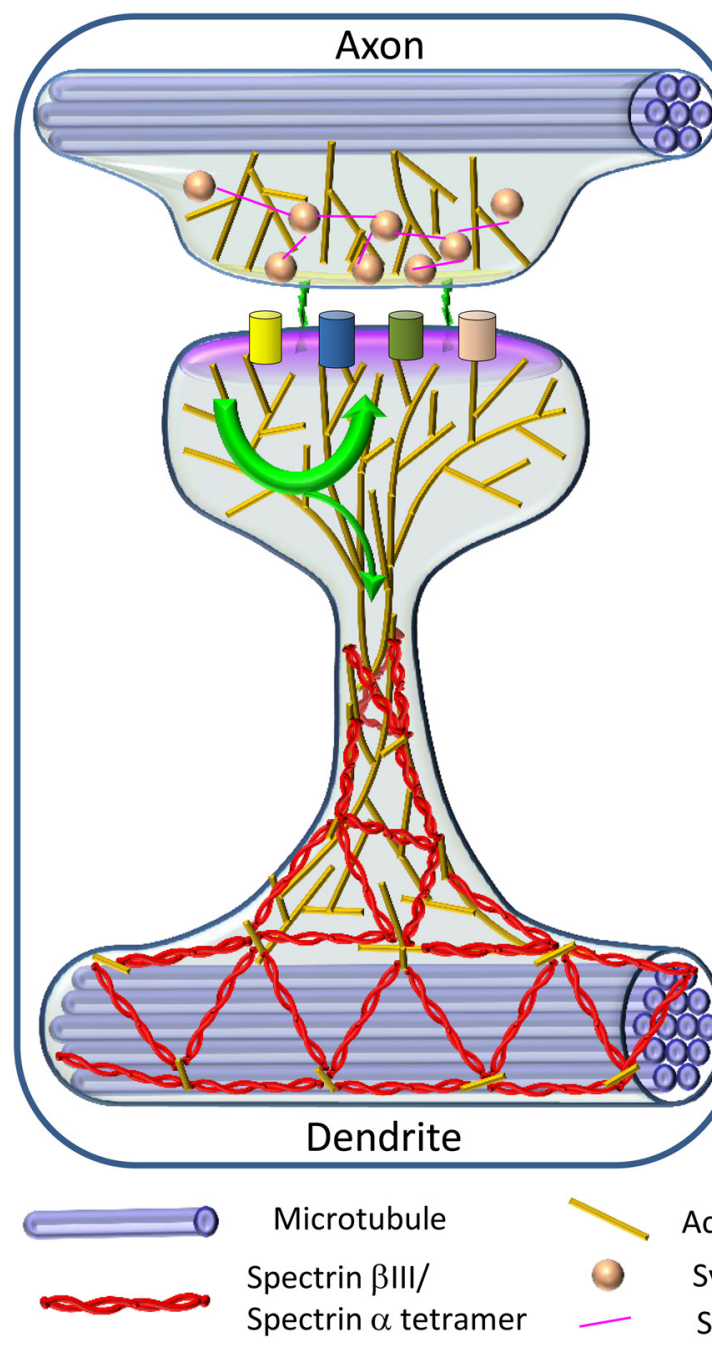

Spectrin $\beta$ III deficiency

Shaft synapses

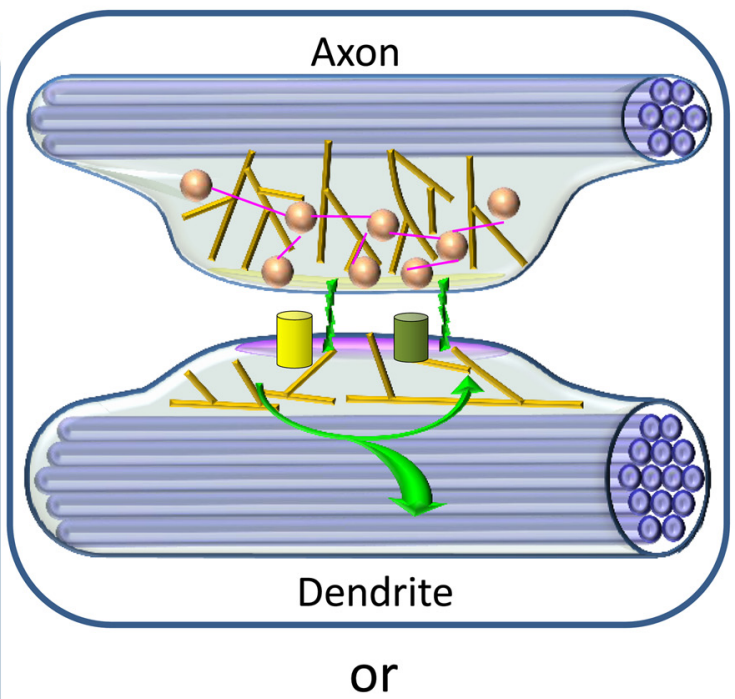

Orphan boutons

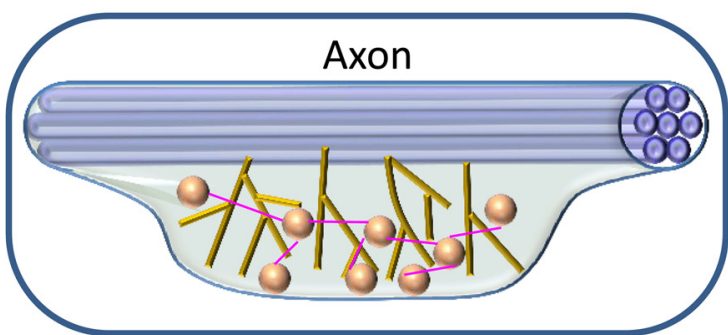

PSD

\section{Synaptic vesicle Synapsin}

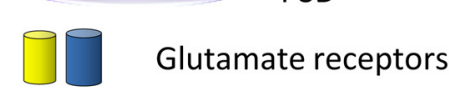

Figure 9. Model of $\beta \mathrm{III}$ spectrin functions in determination of the dendritic spine shape. Left, $\beta$ III spectrin-containing tetramers together with actin filaments form a membrane skeleton in the dendrite and at the base and neck of dendritic spines. This network helps to stabilize the dendritic spine base and constrict the dendritic spine neck. A narrow neck forms a diffusion barrier that controls biochemical and electrical communication through the spine neck and limits a loss of the turning over PSD components from the spine head (green arrow). Right, In the absence of functional $\beta \mathrm{III}$ spectrin, the constricted neck is not formed, leading to an increased formation of shaft synapses (top) and nonsynaptic boutons (bottom). Uncontrolled communication between the synapse and the parent dendrite in shaft synapses results in increased amplitudes of spontaneous mEPSCs and a partial loss of postsynaptic components from the synapse (green arrow).

niques have been figured out (Whelan and Bell, 2015; Wegel et al., 2016), we are inclined to give more credit to PREM data regarding actin filament organization in dendritic spines. In general, although the periodic actin-spectrin patterns are visually appealing, we lean toward the opinion (Qu et al., 2017) that the periodicity of the actin-spectrin cytoskeleton is not as important as its presence. It seems likely that these regular actin-spectrin patterns result from passive stretching of an otherwise disordered actin-spectrin network by longitudinal tension present in the axon (Krieg et al., 2017) and other cellular locations.

Consistent with our structural data suggesting that $\beta$ III spectrin may play an important role in dendritic spine bases and necks, our functional data suggest that $\beta$ III spectrin helps to constrict the dendritic spine neck. We show that a loss of $\beta$ III spectrin in neurons leads to a conversion of spiny synapses to shaft synapses, a predicted outcome of neck constriction failure. The constricted neck of a mushroom-shaped dendritic spine is thought to act as a diffusion barrier (Bloodgood and Sabatini, 2005; Ashby et al., 2006). This idea is supported by the correlation between the spine neck width and the rate of redistribution of fluorescent markers (Takasaki and Sabatini, 2014; Tønnesen et al., 2014). Moreover, neuron activity can modulate the neck geometry (Tønnesen et al., 2014). Our results suggest that the reverse is also true: synaptic activity is affected by the presence or absence of the neck. Specifically, we found that, after $\beta$ III spectrin knockdown, dendritic spines are collapsed onto parent dendrites to form shaft synapses, which results in increased mEPSC amplitudes. Thus, it appears that synaptic activity and spine neck geometry are connected by a feedback loop. Because our data suggest that neck maintenance depends on $\beta$ III spectrin functions, an interesting question for the future is how synaptic activity can regulate $\beta I I I$ spectrin functions to affect the neck shape.

Our results showing a partial loss of PSD95 from synapses and increased mEPSC amplitudes after depletion of $\beta$ III spectrin can be explained by an impaired diffusion barrier between the synapse and the dendrite. A decrease of PSD95 in synapses of $\beta I I I$ spectrin-depleted neurons reflects its redistribution and not an 
overall loss because the total level of PSD95 in the mouse brain is not significantly changed after $\beta$ III spectrin knock-out (Stankewich et al., 2010). Considering that PSD95 is the major scaffolding protein in the PSD, other PSD proteins may be also poorly retained in $\beta$ III spectrin-deficient neurons. Indeed, some postsynaptic proteins were found to be diminished in synaptosomal fractions from brain tissues of SCA5 patients compared with normal tissues (Ikeda et al., 2006). In addition to regulating the spine neck width, $\beta$ III spectrin may also contribute to retention of postsynaptic proteins by capturing "trying-to-escape" proteins through direct protein-protein interactions (Jackson et al., 2001; Ikeda et al., 2006; Armbrust et al., 2014). Furthermore, an increase in mEPSC amplitudes after $\beta$ III spectrin knockdown is a predicted outcome of transformation of spiny synapses to shaft synapses (Segal, 2010) if spine necks act as a barrier for synaptic currents from the synapse to the dendrite. Consistent with this idea and in parallel with our results, conditional knock-out of the Arp2/3 complex in the mouse brain led to a loss of dendritic spines, accumulation of shaft synapses, and increased amplitudes and frequencies of mEPSCs in the brain cortex (Kim et al., 2015). Two effects of $\beta$ III spectrin knockdown observed in our study (a loss of PSD components and an increased number of shaft synapses) are expected to have opposite effects on the mEPSC amplitude. Because mEPSC amplitudes actually increase after $\beta$ III spectrin depletion, the effect of shaft synapse formation apparently overwhelms that of partial PSD disassembly. The partial loss of postsynaptic proteins may also be a protective measure initiated in the neurons to avoid excitotoxicity (Segal, 2010). However, a more complex system of feedback responses at the synapse may contribute to the final synaptic activity (Tønnesen and Nagerl, 2016).

Two human genetic disorders, SCA5 and SPARCA1, are linked to mutations in the SPTBN2 gene encoding $\beta$ III spectrin. Several models have been proposed to link SCA5 and SPARCA1 pathology to $\beta$ III spectrin functions. They include defective stabilization of postsynaptic proteins through direct interaction with $\beta$ III spectrin, aberrant interdigitation of dendritic trees, smaller dendrite diameters, altered transmembrane channel expression, aberrant membrane trafficking, and inability of glia (which does not express $\beta$ III spectrin) to uptake glutamate (for review, see Perkins et al., 2016). However, these hypotheses have significant weaknesses. For example, SCA5-associated $\beta$ III spectrin mutations do not impair the biochemical interaction of $\beta$ III spectrin with postsynaptic proteins, which were proposed to be stabilized by $\beta$ III spectrin (Jackson et al., 2001; Armbrust et al., 2014), and only one SCA5-related $\beta$ III spectrin mutation is expected to affect traffic of membrane organelles (Holleran et al., 2001). In this study, we were unable to document the presence of $\beta$ III spectrin in the close proximity to the synapse by immuno-EM, thus questioning the idea of $\beta$ III spectrin-dependent stabilization of transmembrane postsynaptic proteins. However, direct interaction of $\beta$ III spectrin with postsynaptic proteins may play a role in their recycling through various endocytic compartments located further away from the synapse. This function may be especially important in Purkinje neurons, where a higher fraction of dendritic spines contains $\beta$ III spectrin in their heads. Overall, our data do not exclude the idea that other previously noted aberrancies contribute to SCA5 and SPARCA1 disease pathology, but suggest that the primary defect is likely linked to the impaired morphogenesis of dendritic spines.

Our hypothesis explaining pathology of SCA5 and SPARCA1 syndromes suggests that $\beta$ III spectrin functions as a core part of the membrane-associated cytoskeleton in dendrites, which is necessary to maintain the constricted shape of the dendritic spine neck, which in turn controls the exchange of signaling molecules between the spine head and the parent dendrite (Fig. 9, left). In particular, the neck may help to retain postsynaptic components within the spine head by preventing their leakage into the parent dendrite. In the absence of $\beta$ III spectrin, spine necks expand and PSDs collapse onto dendrite shafts, thus converting spiny synapses to shaft synapses (Fig. 9, right). Because of deficiency of the diffusion barrier in this situation, the excitation strength is not controlled and may exceed acceptable limits, thus leading to excitotoxicity. The role of $\beta$ III spectrin as a part of the membrane skeleton explains how different $\beta$ III spectrin mutations, as long as they impair the ability of $\beta$ III spectrin to assemble a functional actin-spectrin network, can cause similar neuronal phenotypes.

In the brain, $\beta$ III spectrin has the highest expression level in the cerebellum, explaining the predominance of ataxic symptoms in patients with SCA5 and SPARCA1. Consistent with $\beta$ III spectrin having the second highest expression level in the cerebral cortex, both motor and cognitive deficits have been associated with the SPARCA1 syndrome (Lise et al., 2012). Clinical manifestation of hippocampal malfunctions has not been reported in these disorders, probably because it might be difficult to detect such deficits on the background of ataxia and mental retardation. Nonetheless, functions of $\beta$ III spectrin are likely conserved among different types of neurons, as suggested by similar subcellular localization of $\beta$ III spectrin and key features of $\beta$ III spectrin deficiency (a loss of dendritic spines, simplification of the dendritic tree and aberrant synaptic transmission) in hippocampal and cortical neurons in culture (this study) and Purkinje and cortical neurons in vivo (Stankewich et al., 1998; Perkins et al., 2010; Gao et al., 2011; Lise et al., 2012).

\section{References}

Amor V, Zhang C, Vainshtein A, Zhang A, Zollinger DR, Eshed-Eisenbach Y, Brophy PJ, Rasband MN, Peles E (2017) The paranodal cytoskeleton clusters $\mathrm{Na}^{+}$channels at nodes of Ranvier. Elife 6:e21392. CrossRef Medline

Armbrust KR, Wang X, Hathorn TJ, Cramer SW, Chen G, Zu T, Kangas T, Zink AN, Öz G, Ebner TJ, Ranum LP (2014) Mutant beta-III spectrin causes mGluRlalpha mislocalization and functional deficits in a mouse model of spinocerebellar ataxia type 5. J Neurosci 34:9891-9904. CrossRef Medline

Ashby MC, Maier SR, Nishimune A, Henley JM (2006) Lateral diffusion drives constitutive exchange of AMPA receptors at dendritic spines and is regulated by spine morphology. J Neurosci 26:7046-7055. CrossRef Medline

Bär J, Kobler O, van Bommel B, Mikhaylova M (2016) Periodic F-actin structures shape the neck of dendritic spines. Sci Rep 6:37136. CrossRef Medline

Bennett V, Lorenzo DN (2016) An adaptable spectrin/ankyrin-based mechanism for long-range organization of plasma membranes in vertebrate tissues. Curr Top Membr 77:143-184. CrossRef Medline

Bloodgood BL, Sabatini BL (2005) Neuronal activity regulates diffusion across the neck of dendritic spines. Science 310:866-869. CrossRef Medline

Brown JW, Bullitt E, Sriswasdi S, Harper S, Speicher DW, McKnight CJ (2015) The physiological molecular shape of spectrin: a compact supercoil resembling a Chinese finger trap. PLoS Comput Biol 11:e1004302. CrossRef Medline

Byers TJ, Branton D (1985) Visualization of the protein associations in the erythrocyte membrane skeleton. Proc Natl Acad Sci U S A 82:6153-6157. CrossRef Medline

D’Este E, Kamin D, Göttfert F, El-Hady A, Hell SW (2015) STED nanoscopy reveals the ubiquity of subcortical cytoskeleton periodicity in living neurons. Cell Rep 10:1246-1251. CrossRef Medline

D’Este E, Kamin D, Velte C, Göttfert F, Simons M, Hell SW (2016) Subcortical cytoskeleton periodicity throughout the nervous system. Sci Rep 6:22741. CrossRef Medline 
Dotti CG, Sullivan CA, Banker GA (1988) The establishment of polarity by hippocampal neurons in culture. J Neurosci 8:1454-1468. Medline

Ethell IM, Pasquale EB (2005) Molecular mechanisms of dendritic spine development and remodeling. Prog Neurobiol 75:161-205. CrossRef Medline

Fowler VM (2013) The human erythrocyte plasma membrane: a Rosetta Stone for decoding membrane-cytoskeleton structure. Curr Top Membr 72:39-88. CrossRef Medline

Galiano MR, Jha S, Ho TS, Zhang C, Ogawa Y, Chang KJ, Stankewich MC, Mohler PJ, Rasband MN (2012) A distal axonal cytoskeleton forms an intra-axonal boundary that controls axon initial segment assembly. Cell 149:1125-1139. CrossRef Medline

Gao Y, Perkins EM, Clarkson YL, Tobia S, Lyndon AR, Jackson M, Rothstein JD (2011) Beta-III spectrin is critical for development of Purkinje cell dendritic tree and spine morphogenesis. J Neurosci 31:16581-16590. CrossRef Medline

Hartman KN, Pal SK, Burrone J, Murthy VN (2006) Activity-dependent regulation of inhibitory synaptic transmission in hippocampal neurons. Nat Neurosci 9:642-649. CrossRef Medline

He J, Zhou R, Wu Z, Carrasco MA, Kurshan PT, Farley JE, Simon DJ, Wang G, Han B, Hao J, Heller E, Freeman MR, Shen K, Maniatis T, TessierLavigne M, Zhuang X (2016) Prevalent presence of periodic actinspectrin-based membrane skeleton in a broad range of neuronal cell types and animal species. Proc Natl Acad Sci U S A 113:6029-6034. CrossRef Medline

Holleran EA, Ligon LA, Tokito M, Stankewich MC, Morrow JS, Holzbaur EL (2001) beta III spectrin binds to the Arp1 subunit of dynactin. J Biol Chem 276:36598-36605. CrossRef Medline

Hotulainen P, Llano O, Smirnov S, Tanhuanpää K, Faix J, Rivera C, Lappalainen P (2009) Defining mechanisms of actin polymerization and depolymerization during dendritic spine morphogenesis. J Cell Biol 185: 323-339. CrossRef Medline

Ikeda Y, Dick KA, Weatherspoon MR, Gincel D, Armbrust KR, Dalton JC, Stevanin G, Dürr A, Zühlke C, Bürk K, Clark HB, Brice A, Rothstein JD, Schut LJ, Day JW, Ranum LP (2006) Spectrin mutations cause spinocerebellar ataxia type 5. Nat Genet 38:184-190. CrossRef Medline

Jackson M, Song W, Liu MY, Jin L, Dykes-Hoberg M, Lin CI, Bowers WJ, Federoff HJ, Sternweis PC, Rothstein JD (2001) Modulation of the neuronal glutamate transporter EAAT4 by two interacting proteins. Nature 410:89-93. CrossRef Medline

Jones SL, Korobova F, Svitkina T (2014) Axon initial segment cytoskeleton comprises a multiprotein submembranous coat containing sparse actin filaments. J Cell Biol 205:67-81. CrossRef Medline

Kim IH, Rossi MA, Aryal DK, Racz B, Kim N, Uezu A, Wang F, Wetsel WC, Weinberg RJ, Yin H, Soderling SH (2015) Spine pruning drives antipsychotic-sensitive locomotion via circuit control of striatal dopamine. Nat Neurosci 18:883-891. CrossRef Medline

Kim Y, Sung JY, Ceglia I, Lee KW, Ahn JH, Halford JM, Kim AM, Kwak SP, Park JB, Ho Ryu S, Schenck A, Bardoni B, Scott JD, Nairn AC, Greengard P (2006) Phosphorylation of WAVE1 regulates actin polymerization and dendritic spine morphology. Nature 442:814-817. CrossRef Medline

Kizhatil K, Yoon W, Mohler PJ, Davis LH, Hoffman JA, Bennett V (2007) Ankyrin-G and beta2-spectrin collaborate in biogenesis of lateral membrane of human bronchial epithelial cells. J Biol Chem 282:2029-2037. CrossRef Medline

Korobova F, Svitkina T (2010) Molecular architecture of synaptic actin cytoskeleton in hippocampal neurons reveals a mechanism of dendritic spine morphogenesis. Mol Biol Cell 21:165-176. CrossRef Medline

Krieg M, Stühmer J, Cueva JG, Fetter R, Spliker KA, Cremers D, Shen K, Dunn AR, Goodman MB (2017) Genetic defects in beta-spectrin and tau sensitize $C$. elegans axons to movement-induced damage via torquetension coupling. Elife 6:e20172. CrossRef Medline

Landis DM, Reese TS (1983) Cytoplasmic organization in cerebellar dendritic spines. J Cell Biol 97:1169-1178. CrossRef Medline

Leterrier C, Potier J, Caillol G, Debarnot C, Rueda Boroni F, Dargent B (2015) Nanoscale architecture of the axon initial segment reveals an organized and robust scaffold. Cell Rep 13:2781-2793. CrossRef Medline

Lise S, Clarkson Y, Perkins E, Kwasniewska A, Sadighi Akha E, Schnekenberg RP, Suminaite D, Hope J, Baker I, Gregory L, Green A, Allan C, Lamble S, Jayawant S, Quaghebeur G, Cader MZ, Hughes S, Armstrong RJ, Kanapin A, Rimmer A, et al (2012) Recessive mutations in SPTBN2 implicate
beta-III spectrin in both cognitive and motor development. PLoS Genet 8:e1003074. CrossRef Medline

Machnicka B, Czogalla A, Hryniewicz-Jankowska A, Bogusławska DM, Grochowalska R, Heger E, Sikorski AF (2014) Spectrins: a structural platform for stabilization and activation of membrane channels, receptors and transporters. Biochim Biophys Acta 1838:620-634. CrossRef Medline

Mazock GH, Das A, Base C, Dubreuil RR (2010) Transgene rescue identifies an essential function for Drosophila beta spectrin in the nervous system and a selective requirement for ankyrin-2-binding activity. Mol Biol Cell 21:2860-2868. CrossRef Medline

McAllister AK (2007) Dynamic aspects of CNS synapse formation. Annu Rev Neurosci 30:425-450. CrossRef Medline

Nans A, Mohandas N, Stokes DL (2011) Native ultrastructure of the red cell cytoskeleton by cryo-electron tomography. Biophys J 101:2341-2350. CrossRef Medline

Ohara O, Ohara R, Yamakawa H, Nakajima D, Nakayama M (1998) Characterization of a new beta-spectrin gene which is predominantly expressed in brain. Brain Res Mol Brain Res 57:181-192. CrossRef Medline

Ong K, Wloka C, Okada S, Svitkina T, Bi E (2014) Architecture and dynamic remodelling of the septin cytoskeleton during the cell cycle. Nat Commun 5:5698. CrossRef Medline

Papa M, Bundman MC, Greenberger V, Segal M (1995) Morphological analysis of dendritic spine development in primary cultures of hippocampal neurons. J Neurosci 15:1-11. Medline

Penzes P, Cahill ME, Jones KA, VanLeeuwen JE, Woolfrey KM (2011) Dendritic spine pathology in neuropsychiatric disorders. Nat Neurosci 14: 285-293. CrossRef Medline

Perkins EM, Clarkson YL, Sabatier N, Longhurst DM, Millward CP, Jack J, Toraiwa J, Watanabe M, Rothstein JD, Lyndon AR, Wyllie DJ, Dutia MB, Jackson M (2010) Loss of beta-III spectrin leads to Purkinje cell dysfunction recapitulating the behavior and neuropathology of spinocerebellar ataxia type 5 in humans. J Neurosci 30:4857-4867. CrossRef Medline

Perkins E, Suminaite D, Jackson M (2016) Cerebellar ataxias: beta-III spectrin's interactions suggest common pathogenic pathways. J Physiol 594: 4661-4676. CrossRef Medline

Qu Y, Hahn I, Webb SE, Pearce SP, Prokop A (2017) Periodic actin structures in neuronal axons are required to maintain microtubules. Mol Biol Cell 28:296-308. CrossRef Medline

Sala C, Segal M (2014) Dendritic spines: the locus of structural and functional plasticity. Physiol Rev 94:141-188. CrossRef Medline

Segal M (2010) Dendritic spines, synaptic plasticity and neuronal survival: activity shapes dendritic spines to enhance neuronal viability. Eur J Neurosci 31:2178-2184. CrossRef Medline

Shutova M, Yang C, Vasiliev JM, Svitkina T (2012) Functions of nonmuscle myosin II in assembly of the cellular contractile system. PLoS One 7:e40814. CrossRef Medline

Sidenstein SC, D’Este E, Böhm MJ, Danzl JG, Belov VN, Hell SW (2016) Multicolour multilevel STED nanoscopy of actin/spectrin organization at synapses. Sci Rep 6:26725. CrossRef Medline

Smalley-Freed WG, Efimov A, Burnett PE, Short SP, Davis MA, Gumucio DL, Washington MK, Coffey RJ, Reynolds AB (2010) p120-catenin is essential for maintenance of barrier function and intestinal homeostasis in mice. J Clin Invest 120:1824-1835. CrossRef Medline

Spence EF, Kanak DJ, Carlson BR, Soderling SH (2016) The Arp $2 / 3$ complex is essential for distinct stages of spine synapse maturation, including synapse unsilencing. J Neurosci 36:9696-9709. CrossRef Medline

Stankewich MC, Tse WT, Peters LL, Ch'ng Y, John KM, Stabach PR, Devarajan P, Morrow JS, Lux SE (1998) A widely expressed betaIII spectrin associated with Golgi and cytoplasmic vesicles. Proc Natl Acad Sci U S A 95:14158-14163. CrossRef Medline

Stankewich MC, Gwynn B, Ardito T, Ji L, Kim J, Robledo RF, Lux SE, Peters LL, Morrow JS (2010) Targeted deletion of betaIII spectrin impairs synaptogenesis and generates ataxic and seizure phenotypes. Proc Natl Acad Sci U S A 107:6022-6027. CrossRef Medline

Svitkina T (2007) Electron microscopic analysis of the leading edge in migrating cells. Methods Cell Biol 79:295-319. CrossRef Medline

Svitkina T (2016) Imaging cytoskeleton components by electron microscopy. Methods Mol Biol 1365:99-118. CrossRef Medline

Tada T, Simonetta A, Batterton M, Kinoshita M, Edbauer D, Sheng M (2007) Role of septin cytoskeleton in spine morphogenesis and dendrite development in neurons. Curr Biol 17:1752-1758. CrossRef Medline

Takasaki K, Sabatini BL (2014) Super-resolution 2-photon microscopy re- 
veals that the morphology of each dendritic spine correlates with diffusive but not synaptic properties. Front Neuroanat 8:29. Medline

Tønnesen J, Nagerl UV (2016) Dendritic spines as tunable regulators of synaptic signals. Front Psychiatry 7:101. CrossRef Medline

Tønnesen J, Katona G, Rózsa B, Nägerl UV (2014) Spine neck plasticity regulates compartmentalization of synapses. Nat Neurosci 17:678-685. CrossRef Medline

Uhlen M, Fagerberg L, Hallström BM, Lindskog C, Oksvold P, Mardinoglu A, Sivertsson A, Kampf C, Sjöstedt E, Asplund A, Olsson I, Edlund K, Lundberg E, Navani S, Szigyarto CA, Odeberg J, Djureinovic D, Takanen JO, Hober S, Alm T, et al (2015) Proteomics: tissue-based map of the human proteome. Science 347:1260419. CrossRef Medline

Wegel E, Göhler A, Lagerholm BC, Wainman A, Uphoff S, Kaufmann R, Dobbie IM (2016) Imaging cellular structures in super-resolution with SIM, STED and Localisation Microscopy: a practical comparison. Sci Rep 6:27290. CrossRef Medline

Wegner AM, Nebhan CA, Hu L, Majumdar D, Meier KM, Weaver AM, Webb DJ (2008) N-WASP and the Arp2/3 complex are critical regulators of actin in the development of dendritic spines and synapses. J Biol Chem 283:15912-15920. CrossRef Medline
Whelan DR, Bell TD (2015) Image artifacts in single molecule localization microscopy: why optimization of sample preparation protocols matters. Sci Rep 5:7924. CrossRef Medline

Wilcox KS, Buchhalter J, Dichter MA (1994) Properties of inhibitory and excitatory synapses between hippocampal neurons in very low density cultures. Synapse 18:128-151. CrossRef Medline

Xie Y, Vessey JP, Konecna A, Dahm R, Macchi P, Kiebler MA (2007) The GTP-binding protein Septin 7 is critical for dendrite branching and dendritic-spine morphology. Curr Biol 17:1746-1751. CrossRef Medline

Xu K, Zhong G, Zhuang X (2013) Actin, spectrin, and associated proteins form a periodic cytoskeletal structure in axons. Science 339:452-456. CrossRef Medline

Yadav S, Oses-Prieto JA, Peters CJ, Zhou J, Pleasure SJ, Burlingame AL, Jan LY, Jan YN (2017) TAOK2 kinase mediates PSD95 stability and dendritic spine maturation through septin7 phosphorylation. Neuron 93: 379-393. CrossRef Medline

Zhong G, He J, Zhou R, Lorenzo D, Babcock HP, Bennett V, Zhuang X (2014) Developmental mechanism of the periodic membrane skeleton in axons. Elife 3:e04581. CrossRef Medline 